\title{
West African monsoon intraseasonal activity and its daily precipitation indices in regional climate models: diagnostics and challenges
}

\author{
E. D. Poan ${ }^{1} \cdot$ P. Gachon ${ }^{1} \cdot$ G. Dueymes ${ }^{1} \cdot$ E. Diaconescu ${ }^{1,2} \cdot$ R. Laprise $^{1} \cdot$ \\ I. Seidou Sanda ${ }^{3}$
}

Received: 11 June 2015 / Accepted: 28 January 2016 / Published online: 18 February 2016

(C) The Author(s) 2016. This article is published with open access at Springerlink.com

\begin{abstract}
The West African monsoon intraseasonal variability has huge socio-economic impacts on local populations but understanding and predicting it still remains a challenge for the weather prediction and climate scientific community. This paper analyses an ensemble of simulations from six regional climate models (RCMs) taking part in the coordinated regional downscaling experiment, the ECMWF ERA-Interim reanalysis (ERAI) and three satellite-based and observationally-constrained daily precipitation datasets, to assess the performance of the RCMs with regard to the intraseasonal variability. A joint analysis of seasonal-mean precipitation and the total column water vapor (also called precipitable water- $P W$ ) suggests the existence of important links at different timescales between these two variables over the Sahel and highlights the relevance of using $P W$ to follow the monsoon seasonal cycle. RCMs that fail to represent the seasonal-mean position and amplitude of the meridional gradient of $P W$ show the largest discrepancies with respect to seasonal-mean observed precipitation. For both ERAI and RCMs, spectral decompositions of daily $P W$ as well as rainfall show an overestimation of low-frequency activity (at timescales longer than 10 days) at the expense of the synoptic (timescales shorter than 10 days) activity. Consequently, the
\end{abstract}

E. D. Poan

emmanuel.poan@gmail.com

1 Centre pour l'Étude et la Simulation du climat à l'Échelle Régionale (ESCER), Dép. des sciences de la Terre et de l'atmosphère, Université du Québec à Montréal (UQAM), PO Box 8888, Stn. Downtown, Montreal, QC H3C 3P8, Canada

2 Centre Eau Terre Environnement, Institut national de la recherche scientifique (INRS), Quebec, QC, Canada

3 AGRHYMET Regional Centre, Niamey, Niger effects of the African Easterly Waves and the associated mesoscale convective systems are substantially underestimated, especially over continental regions. Finally, the study investigates the skill of the models with respect to hydro-climatic indices related to the occurrence, intensity and frequency of precipitation events at the intraseasonal scale. Although most of these indices are generally better reproduced with RCMs than reanalysis products, this study indicates that RCMs still need to be improved (especially with respect to their subgrid-scale parameterization schemes) to be able to reproduce the intraseasonal variance spectrum adequately.

Keywords West African monsoon - Regional climate modeling $\cdot$ Intraseasonal variability $\cdot$ Precipitation indices

\section{Introduction}

More than three hundred million people live in West Africa and this population is expected to double in the next two decades. The economy of West Africa is mainly based on the rain-fed agricultural and pastoral sectors, so West Africans and, more specifically, the people of the Sahel, are strongly dependent on the four-month rainfall season that generally occurs between June and September. This dependence seems to have been exacerbated recently, probably due, at least partly, to climate variability and change: local surveys and reports indicate concerns about a later monsoon onset, increasingly severe dry spells and flash floods, destruction of biodiversity, etc. (e.g. IPCC 2013, 2014).

Recognition of the vital role of the West African monsoon (WAM) has led to some international multidisciplinary research projects in recent years, such as AMMA 
(African Monsoon Multidisciplinary Analysis; Redelsperger et al. 2002), THORPEX-AFRICA (THe Observing system Research and Predictability EXperiment; Shapiro and Thorpe 2004), WAMME (West African monsoon modeling and evaluation; Druyan et al. 2010), IRIACC/FACE (International Research Initiative on Adaptation to Climate Change/Faire face Aux Changements Ensemble; http:// face.ete.inrs.ca/). A major objective of these initiatives was to understand the physical mechanisms involved in the WAM variability at different spatial and temporal scales and thus to improve the numerical models used for weather prediction and for climate projections. Special attention has been devoted to the intraseasonal ${ }^{1}$ scales that affect day-today life and economic activities more directly. Three main intraseasonal scales of variability have been studied: (1) the 30-90-day scale, which is an MJO- (Madden and Julian Oscillation; Madden and Julian 1971) like activity (Janicot et al. 2009), (2) the 10-25-day scale (Sultan et al. 2003) involving atmosphere-ocean interactions, and (3) the 1-10day scale, which is driven by meteorological events occurring at synoptic scale to mesoscale, such as the African Easterly Waves (AEWs; Kiladis et al. 2006) and Mesoscale Convective Systems (MCSs; Mathon et al. 2002), respectively.

Short-term weather forecasting and future projection of the WAM intraseasonal activity are a huge challenge for the scientific community (Hourdin et al. 2010) because of the complexity of the dynamical and physical processes of the WAM. Roehrig et al. (2013) pointed out the poor suitability of coarse-mesh Global Climate Models (GCMs) for handling the intraseasonal and meteorological scales overall. Yet, Mathon et al. (2002) highlighted the importance of the meteorological events over the Sahel: about $80 \%$ of the annual rainfall is brought by a relatively small number of MCSs, mainly associated with AEWs through complex physical processes (Cornforth et al. 2009). The representation of such scales requires a more precise description of the physical processes related to surface conditions over land and ocean, the boundary layer, clouds, and also radiation and convection (e.g. see Taylor et al. 2011; Guichard et al. 2009). Therefore, more sophisticated models involving finer resolution and more detailed parameterization (e.g. McCrary et al. 2014) need to be designed for this particular WAM region. Regional modeling is one of these tools and it is expected to provide a better representation of the local or regional weather events than can be obtained from coarse-mesh modeling (Gallée et al. 2004; Paeth et al. 2005), thus offering a way to develop applications for adaptation to and mitigation of specifically severe weather

\footnotetext{
${ }^{1}$ Intraseasonal scale activity refers to phenomena occurring in a time period encompassing 1 to 90 days during any given year.
}

events. For example, Oettli et al. (2011) investigated the perspective of using Regional Climate Models (RCMs) for crop-yield prediction and highlighted a promising result with the RCM ensemble prediction approach. Crétat et al. (2013) assessed the representation of the monsoon physics during intense rainfall events and showed the significant added value of RCMs in comparison with GCMs.

In line with these ideas, the Coordinated Regional Downscaling Experiments (CORDEX, Giorgi et al. 2009) project is one of the leading endeavors aiming to provide a complete and homogeneous dataset describing the recent past and the future of the WAM region. From these simulations, Nikulin et al. (2012) and Gbobaniyi et al. (2013) have shown, for time scales ranging from interannual to seasonal, an added value of RCMs when they are driven by ERA-Interim reanalysis (ERAI; Dee et al. 2011) rather than by coarse-mesh driving boundary conditions.

Fewer studies have targeted the ability of RCMs to reproduce the monsoon intraseasonal events such as rainfall onset and retreat, AEW intermittency, or the precipitation diurnal cycle. Druyan et al. (2010) have shown that reanalysis-driven RCMs are much more realistic (relatively to GCM-driven) in representing the African monsoon dynamics, such as the structure of the African Easterly Jet (AEJ), the low-level circulation and, hence, the humidity and heat transport. Sylla et al. (2010) have investigated the intraseasonal variability of the WAM using $\operatorname{RegCM} 3^{2}$ (Regional Climate Model version 3). They demonstrated the model's ability to represent the WAM dynamics and, more specifically, the AEWs and their related AEJ. Even though this study showed the high potential of RegCM3 to handle very subtle interactions between the AEWs and the $\mathrm{AEJ}$, it was quite limited in terms of quantitative evidence, such as the extent to which this synoptic-scale activity determines the monsoon precipitation. The recent studies by Gbobaniyi et al. (2013), Diallo et al. (2014) and Mounkaila et al. (2015) broadly show a good representation of the WAM onset by RCMs participating in CORDEX. Mariotti et al. (2014) have shown better performance of RCMs in comparison with GCMs in reproducing the AEW activity, but their analysis is qualitative. Crétat et al. (2015) conducted a more detailed analysis on the relationship between AEWs and daily rainfall, using various regional simulations, and revealed the fairly good performance of RCM in terms of spatial and temporal phases. Although a set of arguments tends to confirm the real added value of RCMs, Flaounas et al. (2011) have shown a decisive impact of physical parameterizations on the monsoon onset and precipitation intraseasonal variability, implying

\footnotetext{
${ }^{2}$ RegCM3 is the regional model developed at the International Centre for Theoretical Physics (ICTP).
} 
that substantial work is still needed to calibrate or to adapt RCMs for Africa.

As previously noted, a large part of the WAM precipitation is attributable to intraseasonal activity and, therefore, the ability of RCMs to represent the intraseasonal variability is closely related with their performance regarding the day-to-day rainfall. Parry et al. (2007) highlighted the necessity of understanding and representing these daily rainfall statistics since they are often more useful (than seasonal means) for impact and adaptation studies. Diaconescu et al. (2015) used two ERAI-driven RCMs to analyze the local onset and retreat of the WAM, as well as the daily precipitation statistics such as the occurrences of wet days, consecutive wet and dry days, and extreme rainfall. Their study reveals the difficulty that reanalyses, such as ERAI, have in adequately representing these indices, in particular the statistics of events with precipitation higher than $10 \mathrm{~mm} \mathrm{day}^{-1}$. More recently, a study by Klutse et al. (2015) compared 10 RCMs with observations and noted a generalized weakness of RCMs in producing higher-order daily precipitation statistics such as intensity, frequency or duration. The WAM local onset/retreat is another intraseasonal event of great interest but, until now, it has been the subject of only a few comprehensive assessments, especially at local scale (in contrast with large-scale onset) in RCM simulations. Diaconescu et al. (2015) pointed out the difficulties of RCM simulations as well as reanalyses to simulate the local onset over the Sahel region. In this paper, in order to obtain a more comprehensive idea of the intraseasonality in RCMs and its impacts (quantitatively), a set of daily precipitation indices are evaluated against satellite observations and presented as a performance matrix.

Assessments of the intraseasonal variability may be strongly related to the meteorological variable involved overall in the tropical region. For example, a model with good skill in capturing dynamical AEWs does not necessarily have good skill in capturing the associated convective features (MCSs) since these two phenomena, although strongly interacting, occur at different time and space scales (Fink and Reiner 2003). It has to be added that the interactions between the WAM dynamics and convective processes are complex but determine the monsoon activity overall at synoptic scales (Poan et al. 2014). Investigating the intraseasonal variability therefore requires looking into both dynamical and convective parameters.

This paper will use the integrated-column water vapor (also called Precipitable Water, hereafter $P W$ ) as a proxy integrating the monsoon dynamics and thermodynamics. $P W$ presents the advantage of being relatively better predicted for time scales longer than the diurnal cycle in models (Bock et al. 2007). In addition, Poan et al. (2013) have shown that $P W$ is well suited to following the intraseasonal activity of the WAM, particularly over the Sahel.
Concerning convective activity, the daily total precipitation will be used. While $P W$, as an integrated variable, is sensitive to atmospheric phenomena lasting long enough ( $\sim 3-5$ days) to affect the total column content, precipitation is more affected by shorter scales (less than 3 days). Therefore, combining these two variables allows the whole spectrum of variability to be analyzed, from the longest (up to 90 -day period) to the shortest (1-day period) time scales. Focusing on the climate of the recent past (1989-2008), this paper aims to assess the ability of the RCMs (from available CORDEX runs) to represent the WAM intraseasonal variability spectrum in comparison with observations. This analysis is a step forward in assessing models since a "fair" representation of the monsoon mean state is not sufficient to qualify a model as a "good" one.

The paper is organized as follows. The data and methodology are described in Sect. 2. In Sect. 3, the climatology of the WAM is discussed in terms of $P W$ and precipitation as simulated by RCMs, reanalysis and observations. Section 4 analyses the WAM intraseasonal variability through $P W$ filtered variance and precipitation frequency distribution. In Sect. 5, the WAM local onset/retreat and some daily precipitation indices are evaluated. Finally, Sect. 6 summarizes the main findings and suggests further developments.

\section{Data and methodology}

\subsection{Observational datasets and reanalysis}

The RCM daily precipitation will be evaluated against the Africa Rainfall Climatology version 2 (ARC2; Novella and Thiaw 2012) daily-precipitation data from the Climate Prediction Center (CPC). This is a satellite-based and observationally constrained dataset that covers the African continent (from $40^{\circ} \mathrm{S}$ to $40^{\circ} \mathrm{N}$ and from $20^{\circ} \mathrm{W}$ to $55^{\circ} \mathrm{E}$ ) on a very fine-mesh grid: $0.1^{\circ} \times 0.1^{\circ}$. The dataset is available from 1983 to the present through the CPC site. In order to give some measure of the uncertainty in satellite-based observations, two other sets of satellite-based and observationallyconstrained daily precipitation were used:

- TRMM 3B42 version 6 (Tropical Rainfall Measuring Mission; Huffman et al. 2007) providing 3-hourly precipitations on a $0.25^{\circ}$-mesh grid covering the tropical regions since 1998.

- GPCP-1DD version 1.2 (Huffman et al. 2001) global daily precipitation from the Global Precipitation Climatology Project (GPCP), available from 1998 to present on a $1^{\circ}$-mesh grid.

From previous studies (e.g. Sylla et al. 2012), it is known that observational data have less and less consistency when 
higher order statistics on daily precipitation over West Africa are assessed. Therefore, it became difficult to select one of our satellite data sets as a reference to compare RCMs. However, mainly because of its longer time period, ARC2 will be considered in the majority of analyses, while TRMM and GPCP will help to nuance the comments.

Precipitation and $P W$ from ERAI are also used to compare the RCM-simulated daily fields. The data cover the recent period of 1979 to 2009 and are offered on a $0.75^{\circ}$ mesh grid. It should be borne in mind that there is no station-precipitation assimilation in ERAI, and hence the reanalysis precipitation is a prognostic variable that is a byproduct of the assimilation of other atmospheric variables and the short-term forecast of the ECMWF model.

\subsection{RCM data}

A subset of six CORDEX-Africa RCMs was available in this study for the evaluation of historical experiments. The model boundary conditions were given by ERAI for the CORDEX project evaluation and by simulations from three Coupled GCMs for the historical CORDEX project, namely CanESM2 (Arora et al. 2011), MPIESM-MR (Jungclaus et al. 2013) noted here as MPI, and EC-EARTH (Hazeleger et al. 2012). To avoid any confusion, most of the results from these GCM-driven simulations will be shown in the Appendix and so will be commented only briefly. The RCM simulations are provided on a $0.44^{\circ}$ horizontal grid. Details of each RCM are summarized in Table 1. The CRCM5 (Hernández-Díaz et al. 2013; Laprise et al. 2013) data were acquired directly from the Centre pour l'Étude et la Simulation du Climat à l'Échelle Régionale (ESCER Centre) at UQAM (http:// www.escer.uqam.ca/), CanRCM4 (Scinocca et al. 2016) data were provided by the Canadian Centre for Climate Modelling and Analysis division of the Climate Research Branch of Environment Canada (CCCma/CRB/EC; http:// www.ec.gc.ca/ccmac-cccma/), and the other RCM data were obtained through the Earth System Grid Federation (ESGF; for details see http://www.cordex.org/index.php/ output). Note that the HIRHAM5 $P W$ field was not available at the time of the present study.

\subsection{Methodology and definitions}

As shown in the data section, several RCMs were involved in this analysis with the main purpose of highlighting their consistency versus their spread due to the different choices made for each RCM (as shown in the review by Paeth et al. 2011). Ideally, all the simulations involved in the CORDEX project should have been used. However, only 6 of all available RCMs could be selected from the database, mainly because of the necessity of having $P W$. In the discussion, attention will be paid to model spreads which, in turn, will be raised as key topics for future improvements.

Most of the analyses shown in this paper involve conversions between time and frequency domains. For temporal filtering, the Lanczos filter described by Duchon (1979) was used in different modes such as high-pass ("hp") and band-pass ("bp") filtering. Since boundary effects are a critical issue in data filtering, it is worth mentioning that the filtering was applied to all the data ranging from January to December of each year, even though only the summer rainy months (June-July-August-September, JJAS) were kept for the analysis, thus reducing spurious boundary effects. The JJAS time period corresponds to the main humid period over the WAM region, especially in the Sahel/Sudan area (e.g. Sultan et al. 2003).

To analyze the periodicities involved in the intraseasonal anomalies, we used a Fast Fourier Transform (FFT) algorithm. This classical method allows any time-discrete signal to be described through its power spectral density (PSD). The contribution of each frequency to the total time variance of the signal can thus be analyzed. The choice was made to plot the normalized PSD for each dataset. By doing this, we could compare the relative importance of each time scale of the different models regardless of their initial differences in amplitude.

Wavelet analysis is also used in this study. The protocol defined by Torrence and Compo (1998) was applied to the daily rainfall at each grid point, then spatially averaged over specific regions. This technique provides an overview of the contributions of different intraseasonal scales represented in RCMs, ERAI and observations for a specific year, such as 2009 , which was marked by intense, sustained rainy events over West Africa. Sultan et al. (2003) showed that such an analysis was particularly useful to reveal the WAM intraseasonal modes. It is worth mentioning that the FFT and the wavelet analysis were applied to the intraseasonal signal, defined for each variable as its 90-day highpass filtered (hp90) variance, as used in recent studies (e.g. Chauvin et al. 2010).

The second part of our analysis is devoted to the assessment of daily precipitation indices. Diaconescu et al. (2015) give details on the background concepts supporting the selection of these indices, while Gachon et al. (2007) show the climatology of such indices using numerous stations over West Africa. The Root Mean Square Error (RMSE, against ARC2 used as reference dataset) is used as the metric and the information is summarized using a condensed performance matrix (e.g. Gleckler et al. 2008). For each index, the matrix records the ratio of each model RMSE and the highest RMSE among all models.

The WAM onset corresponds to a significant decrease in precipitation near the Guinea coast $\left(5-10^{\circ} \mathrm{N}\right)$ and, conversely, its durable establishment over the northern 


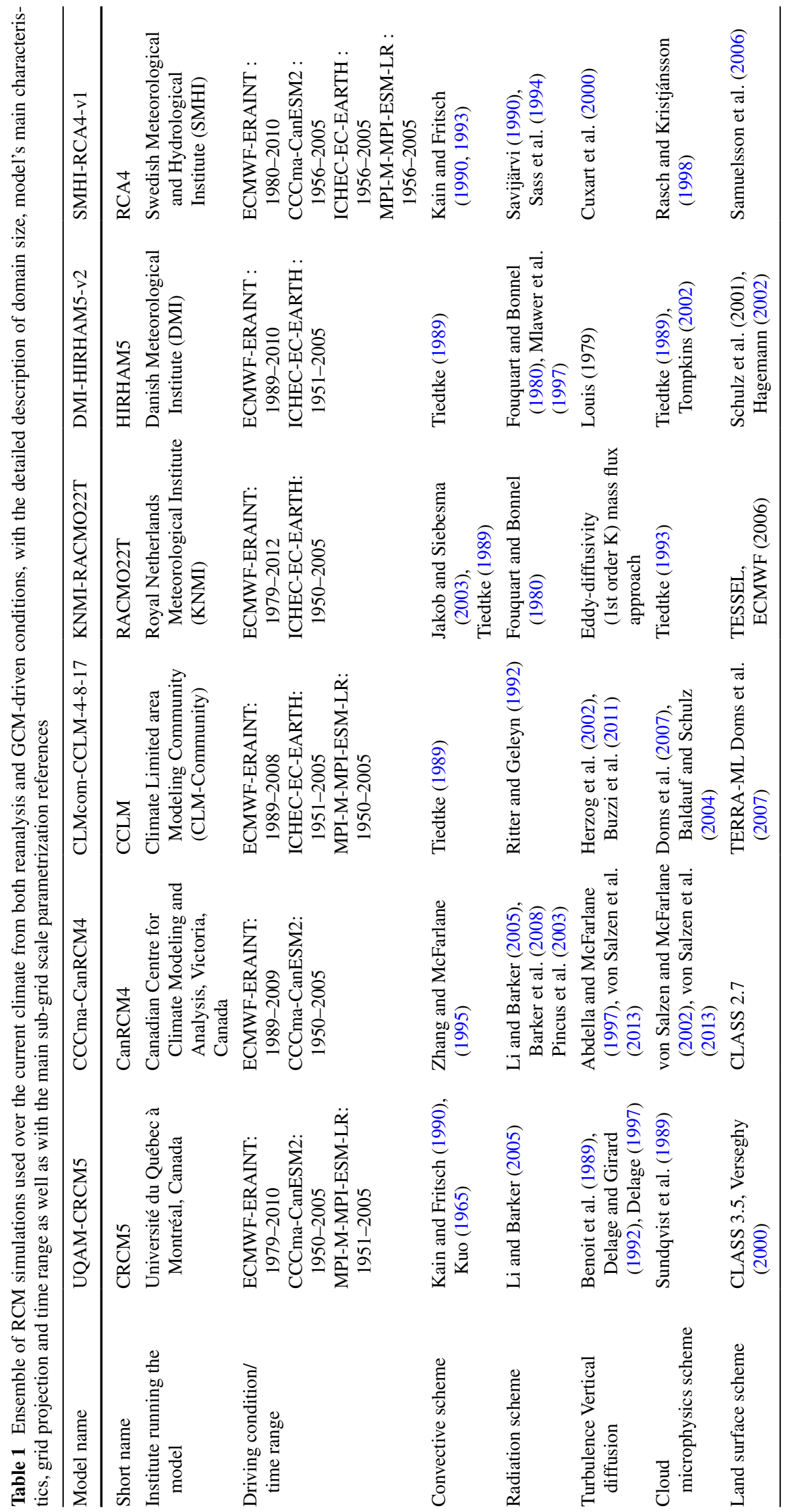


latitudes $\left(10-17^{\circ} \mathrm{N}\right)$. Sultan et al. (2005) highlighted what was at stake in the region's socio-economic life during the onset, presenting it as the most important intraseasonal event, crucial for agro-pastoral yields. Therefore it is important for RCMs to be able to capture the monsoon onset (and its retreat) for both present and future climates. In the literature on the WAM (e.g. Vellinga et al. 2013; Fitzpatrick et al. 2015), two main features can be used for detecting the onset: (1) the large-scale onset that focuses on the shift (or jump) of the sustained rainy band from its Guinean position $\left(\sim 5^{\circ} \mathrm{N}\right)$ to a Sudanese position $\left(\sim 10^{\circ} \mathrm{N}\right)$, (2) the local onsets are related to more agricultural purposes and represent the effective start of sustained rainfall at a specific location. The large-scale precipitation onset has been quite widely analyzed, in particular in CORDEX simulations (among others, Gbobaniyi et al. 2013; Nikulin et al. 2012; Diaconescu et al. 2015) and most RCMs tend to improve the onset occurrence in comparison with ERAI and GCMs. The local onset is more complicated to reproduce since precipitation structures are more affected by smaller scale processes in this case (Marteau et al. 2011). Fitzpatrick et al. (2015) recently studied this issue by comparing different data and/or definitions, and revealed that there was poor consistency in local onset while large-scale onsets were quite well correlated. In this paper, the focus is on local onset and the intention is to see how good RCM skills are at smaller scales, and hence whether they can be used in agricultural domains, for instance.

The local onset computation is based on the method of Diaconescu et al. (2015) here, which takes its inspiration from a study by Liebmann and Marengo (2001). An onset function is defined, for each grid point, as the cumulative sum of daily precipitation anomalies from day $1\left(1^{\text {st }}\right.$ January) to day 365 ( $31^{\text {st }}$ December). The anomalies are computed against the grid-point climatological mean, which, in our case, is a 20-year mean. Physically, this definition allows the weight (or impact) of any daily rainy event on the whole season state to be taken into account at the time it occurs. In addition, from an agricultural point of view, a given event will not be "useful" if (1) it is not sufficient to change the trajectory of the onset function or (2) it is not sustained by companion events to keep the function moving in the same direction. From this function, the onset date is detected as the day the function reaches its minimum and, conversely, its maximum for the retreat. By comparison, Vellinga et al. (2013) defined their local onset as the date when a certain threshold (e.g. $20 \%$ ) of the average seasonal total rainfall was reached at a given location. Finally, given that there is still no consensus defining the WAM local (and even regional) onset, it has to be agreed that one might be cautious when analyzing the onset issues from different approaches (as argued by Fitzpatrick et al. 2015).
The time average will be computed more often over 1989-2008 (except for TRMM and GPCP, 1998-2008). Since ARC2 is the longest available set of observational data, it will be considered as the reference for precipitation, while ERAI will be the reference for $P W$. Bock et al. (2007) have shown the accuracy of ERAI $P W$ using ground-based GPS observations over West Africa.

\section{Climatological background: column-integrated humidity and monsoon precipitation}

\subsection{On the relationship between precipitable water and observed rainfall}

The physical link between $P W$ and tropical rainfall has been inferred and discussed by recent studies (Holloway and Neelin 2007; Neelin et al. 2009). The amount of $P W$ and its time variations integrate thermodynamic (specific humidity) and dynamic (wind) processes, respectively, and therefore it can provide suitable information on the evolution of the monsoon. More specifically, over the Sahel, the humidity supply is the essential factor for building up moist static energy since the heat reservoir is already huge. Bock et al. (2007) showed high correlations between the WAM rainfall and $P W$ at 5 ground-based GPS stations, both at seasonal and intraseasonal scales. It was also inferred by Bock et al. (2008) that no rainfall occurs when $P W$ is smaller than $30 \mathrm{~mm}$. At synoptic scale, Poan et al. (2013) have shown that $P W$ is particularly well suited for the detection and monitoring of the AEW dynamics, as well as the associated precipitation.

More generally, over tropical oceanic regions, Holloway and Neelin (2007) showed that, considering its relatively long autocorrelation time, $P W$ can integrate both synoptic and mesoscale physics, while precipitation is more sensitive to shorter (a few hours) time-scale processes. Finally, $P W$ is expected to provide a "smoothed" view of the relatively chaotic patterns of precipitation. In this paper, the performance of RCMs in representing $P W$ consistently with rainfall is discussed.

Figure 1a displays ERAI $P W$ JJAS climatology (colors represent $\mathrm{mm}$ ) and variance (contours in $\mathrm{mm}^{2}$ ). The thick green line delimits the 30-mm threshold, below which no significant rainfall is observed. The notable meridional gradient of humidity is delimited by southern (south of $\left.15^{\circ} \mathrm{N}\right)$ values higher than $40 \mathrm{~mm}$ and low values $(<30 \mathrm{~mm})$ north of $20^{\circ} \mathrm{N}$. In between, in the Sahel area, lies the sharp gradient but also the band of high variability. For example, Table 2 shows a variation of approximately $22 \mathrm{~mm}$ of $P W$ between $10^{\circ} \mathrm{N}$ and $20^{\circ} \mathrm{N}$ around the Greenwich meridian, with an increase between $15^{\circ} \mathrm{N}$ and $20^{\circ} \mathrm{N}$. The seasonal-mean precipitation displayed in Fig. 1b (ARC2) 
(a) JJAS PW, 1989-2008 - ERAI

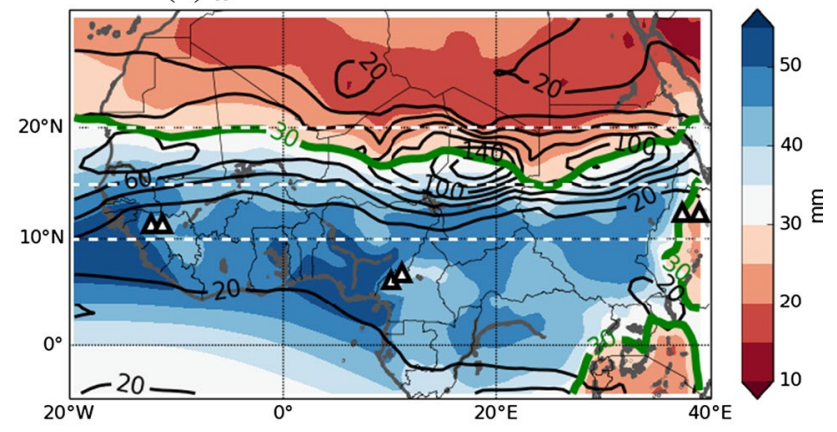

(b) JJAS RR, 1989-2008 - ARC2

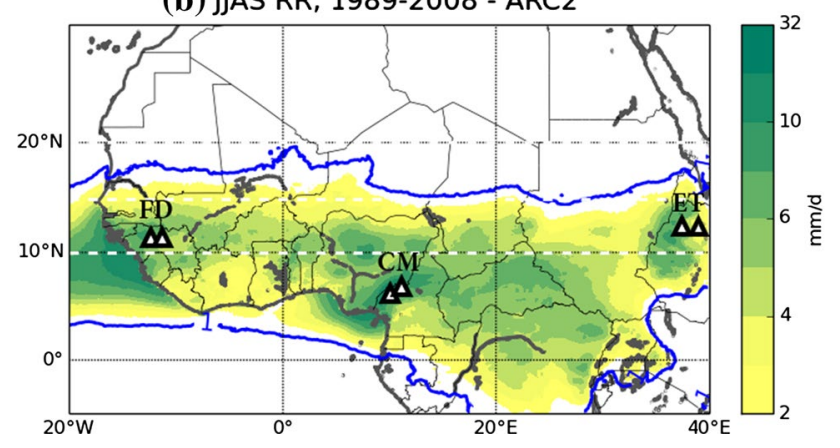

Fig. 1 1989-2008 Seasonal (June-July-August-September, JJAS) mean fields. a ERAI $P W$ (colors in $\mathrm{mm}$ ) and variance (contours in $\mathrm{mm}^{2}$ ); the thick green line delimits the $30-\mathrm{mm} P W$ threshold below which no significant rainfall is observed. b ARC2 precipitation (colors in $\mathrm{mm} \mathrm{day}^{-1}$ ); the thick blue lines delimit the $1 \mathrm{~mm}$ day $^{-1}$ precipitation. The triangles indicate the location of three main topographical features: $F D$ Fouta Djallon, $C M$ Cameroon Mountain, $E T$ Ethiopian Highlands

is consistent with the overall patterns of $P W$ from ERAI showing a south-to-north decrease. Over the Sahel, rainfall seems to occur only where $P W$ exceeds $30 \mathrm{~mm}$ (south of $20^{\circ} \mathrm{N}$ ). The northern contour of $1 \mathrm{~mm} \mathrm{day}^{-1}$ follows the maximum of $P W$ variance remarkably well (Fig. 1a). Over the topography of Guinea, Cameroon and Ethiopia, the lower values of $P W$ are anti-correlated with the maximum in precipitation.

Despite a fair representation of $P W$ in ERAI (as noted by Bock et al. 2007), Fig. 2a, b as well as Table 2 clearly show the difficulties of ERAI in reproducing rainfall consistent with observations. The rain belt is particularly far south and the $1 \mathrm{~mm}$ day $^{-1}$ contour barely goes north of $15^{\circ} \mathrm{N}$. Precipitation of only $0.9 \mathrm{~mm} \mathrm{day}^{-1}$ occurs at $15^{\circ} \mathrm{N}$ (near the Greenwich meridian) while ARC2 shows $2.5 \mathrm{~mm} \mathrm{day}^{-1}$ (see Table 2). The southward position of the rainfall is particularly striking west of $5^{\circ} \mathrm{E}$. The seasonal maximum is trapped south of $10^{\circ} \mathrm{N}$. Regarding the observational data shown in Table 2, although the TRMM and ARC2 datasets are consistent with each other, the average daily precipitation rate appears higher in the former than in the latter. However, TRMM climatology uses only 11 years
(1998-2008) and that might slightly influence the seasonalmean values, as the last decade has been more humid with more extreme rainfall over the Sahel than previous decades (e.g. Mouhamed et al. 2013; Sarr et al. 2014).

Being a reanalyzed variable, ERAI $P W$ agrees with observations (e.g. radio-sounding of humidity) quite well and can be regarded as being as accurate as GPS observations (as shown by Poan et al. 2013). On the other hand, ERAI rainfall shows large discrepancies with respect to observed data, at least over the Sahel. In other words, although necessary, an accurate representation of the monsoon large-scale dynamics and thermodynamics is not sufficient to produce an accurate precipitation field. It also implies that the model physical parameterizations are very important, specifically over the Sahel where diabatic processes (e.g. boundary layer, cumulus convection) are important.

\subsection{Joint analysis of the seasonal $P W$ and precipitation in regional models}

Figure 2 presents the JJAS climatological mean for $P W$ (upper panels) and precipitation (lower panels) for ERAI and as simulated by five RCMs driven by ERAI. Table 2 also gives details on $P W$ and rainfall (mean values and meridional gradients), sampling the monsoon region at different locations from East to West: inland $\left(15^{\circ} \mathrm{E}\right)$, Greenwich $\left(0^{\circ} \mathrm{E}\right)$ and over the western coast $\left(15^{\circ} \mathrm{W}\right)$, all along the $15^{\circ} \mathrm{N}$ parallel. The indices are computed using a $2^{\circ}$ latitude/ longitude square $(\sim 5 \times 5 \mathrm{RCM}$ grid points $)$ centered on each location. This table aims to give a quantitative assessment of RCM behaviors in the critical Sahel band where both humidity and precipitation gradients are strong, and therefore difficult to reproduce. The seasonal-mean structure of $P W$ shown in Fig. 2 implies that all RCMs represent the climatology (position and amplitude) described in Sect. 3 a quite well, namely the sharp north-south humidity gradient as well as the Sahel zonal band of high variability. In fact, RCM-simulated $P W$ is of the same order as ERAI, except in the CCLM model, where it appears particularly higher. On the other hand, more discrepancies and dispersion between RCMs appear when $P W$ variance is considered. Over the Sahel, Couvreux et al. (2010) showed that more than 75 ( $88 \%)$ of $P W$ mean (variance) is brought by levels below $700 \mathrm{hPa}$, suggesting that a good representation of low-level circulation is crucial to obtaining the right quantities of $P W$. In agreement with previous studies (e.g. Sylla et al. 2009), it can be speculated here that most RCMs, because of improving local/regional processes, tend to better simulate the low-level circulation, together with the mean temperature and humidity gradients. From a more detailed analysis, Table 2 reveals that the spatial distribution is reproduced by RCMs with variable levels of 
Table 2 JJAS climatology of different indices computed using daily precipitation and $P W$ from RCMs, ERAI and satellites observations, and spatially averaged over three specific locations

\begin{tabular}{|c|c|c|c|c|c|c|c|c|}
\hline \multirow[t]{2}{*}{ Dataset } & \multicolumn{5}{|c|}{ Precipitable water $(P W, \mathrm{~mm})$} & \multicolumn{3}{|c|}{ Precipitation $\left(\mathrm{RR}, \mathrm{mm} \mathrm{day}^{-1}\right)$} \\
\hline & Longitude & $P W$ & $\sigma^{2}(P W)$ & $\Delta_{P W}(10 N)$ & $\Delta_{P W}(20 N)$ & $\mathrm{RR}$ & $\Delta_{R R}(10 N)$ & $\begin{array}{l}\Delta_{R R} \\
(20 N)\end{array}$ \\
\hline \multirow[t]{3}{*}{$\mathrm{ARC} 2$} & $15^{\circ} \mathrm{W}$ & & & & & 2.7 & +8.5 & -2.2 \\
\hline & $0^{\circ} \mathrm{E}$ & & & & & 2.5 & +2.5 & -1.3 \\
\hline & $15^{\circ} \mathrm{E}$ & & & & & 1.3 & +3.7 & -0.7 \\
\hline \multirow[t]{3}{*}{ TRMM } & $15^{\circ} \mathrm{W}$ & & & & & 3.5 & +9.0 & -3.1 \\
\hline & $0^{\circ} \mathrm{E}$ & & & & & 3.2 & +3.2 & -2.4 \\
\hline & $15^{\circ} \mathrm{E}$ & & & & & 1.7 & +4.1 & -1.0 \\
\hline \multirow[t]{3}{*}{ ERAI } & $15^{\circ} \mathrm{W}$ & 46.5 & 52.6 & +7.3 & -15.7 & 1.6 & +9.0 & -1.5 \\
\hline & $0^{\circ} \mathrm{E}$ & 42.4 & 25.8 & +8.1 & -13.7 & 0.9 & +3.3 & -0.8 \\
\hline & $15^{\circ} \mathrm{E}$ & 39.3 & 101.4 & +8.8 & -14.0 & 1.2 & +4.7 & -0.9 \\
\hline \multirow[t]{3}{*}{ CRCM5 } & $15^{\circ} \mathrm{W}$ & 49.4 & 51.0 & +8.3 & -17.1 & 4.2 & +19.3 & -0.2 \\
\hline & $0^{\circ} \mathrm{E}$ & 40.2 & 66.3 & +12.7 & -19.0 & 1.2 & +4.3 & -1.1 \\
\hline & $15^{\circ} \mathrm{E}$ & 32.3 & 108.9 & +15.1 & -13.4 & 0.5 & +4.1 & -0.5 \\
\hline \multirow[t]{3}{*}{ CanRCM4 } & $15^{\circ} \mathrm{W}$ & 44.6 & 54.2 & +8.4 & -22.8 & 3.4 & +12.5 & -2.8 \\
\hline & $0^{\circ} \mathrm{E}$ & 43.3 & 40.3 & +4.8 & -13.5 & 5.5 & +1.3 & -2.1 \\
\hline & $15^{\circ} \mathrm{E}$ & 38.9 & 65.7 & +5.3 & -13.7 & 3.7 & +2.5 & -2.9 \\
\hline \multirow[t]{3}{*}{ RCA4 } & $15^{\circ} \mathrm{W}$ & 49.4 & 34.5 & +6.6 & -17.4 & 6.2 & +12.3 & -5.9 \\
\hline & $0^{\circ} \mathrm{E}$ & 42.5 & 39.5 & +7.7 & -12.5 & 2.9 & +2.7 & -1.1 \\
\hline & $15^{\circ} \mathrm{E}$ & 34.0 & 123.1 & +11.4 & -15 & 1.5 & +3.7 & -1.3 \\
\hline \multirow[t]{3}{*}{ RACMO22T } & $15^{\circ} \mathrm{W}$ & 48.6 & 40.7 & +5.3 & -12.0 & 2.7 & +11.4 & -2.3 \\
\hline & $0^{\circ} \mathrm{E}$ & 47.5 & 29.3 & +3.4 & -12.0 & 5.8 & +0.4 & -5.2 \\
\hline & $15^{\circ} \mathrm{E}$ & 45.5 & 439 & +18.7 & -15.3 & 3.4 & +4.5 & -3.1 \\
\hline \multirow[t]{3}{*}{ HIRHAM4 } & $15^{\circ} \mathrm{W}$ & & & & & 3.2 & +20.9 & -2.7 \\
\hline & $0^{\circ} \mathrm{E}$ & & & & & 5.1 & +4.1 & -4.4 \\
\hline & $15^{\circ} \mathrm{E}$ & & & & & 2.9 & +3.5 & -2.7 \\
\hline \multirow[t]{3}{*}{ CCLM } & $15^{\circ} \mathrm{W}$ & 49.1 & 67.0 & +7.8 & -12.0 & 1.3 & +14.2 & -1.2 \\
\hline & $0^{\circ} \mathrm{E}$ & 50.63 & 25.9 & +2.5 & -10.7 & 4.6 & +1.8 & -3.9 \\
\hline & $15^{\circ} \mathrm{E}$ & 49.0 & 43.2 & +2.5 & -11.9 & 3.0 & +2.3 & -2.6 \\
\hline
\end{tabular}

These locations (varying in longitude "Long") have been sampled at $15^{\circ} \mathrm{W}$ (coast), $0^{\circ} \mathrm{E}$ (Greenwich) and $15^{\circ} \mathrm{E}$ (Central Africa). Their latitude extension is $2^{\circ}$ centered on the reference $15^{\circ} \mathrm{N} . P W_{15 \mathrm{~N}}$ and $\sigma_{15 \mathrm{~N}}^{2}$ refer to $P W$ mean and variance for each location. To compute the meridional southern (between $10^{\circ} \mathrm{N}$ and $15^{\circ} \mathrm{N}$ ) and northern (between $15^{\circ} \mathrm{N}$ and $20^{\circ} \mathrm{N}$ ) "gradients" (without distance normalization) for each reference longitude location described previously, we use $\Delta_{\chi}(20 N)=\chi(20 N)-\chi(15 N)$ and $\Delta_{\chi}(10 N)=\chi(10 N)-\chi(15 N)$ where $\chi$ states for $P W$ or $R R$ (precipitation in mm/day). Note HIRHAM5 $P W$ was not available success, especially near the Greenwich meridian and inland $\left(15^{\circ} \mathrm{E}\right)$, where the differences with ERAI are quite substantial. However, it is important to keep in mind that $P W$ is a "freely" simulated variable in RCMs (inside the domain) while, in ERAI, it should be strongly constrained by the observation data assimilation procedure.

Over the Sahel, the low-level temperature gradient explains the existence of the African Easterly Jet (AEJ) near $600 \mathrm{hPa}$ (Thorncroft and Blackburn 1999). That temperature gradient combined with the humidity gradients constitute a baroclinic energy reservoir that is strongly involved in the genesis and the development of summer atmospheric disturbances such as AEWs (Leroux and Hall
2009). Consequently, it seems important that RCMs reproduce this baroclinic mean state over the Sahel, which can be inferred through $P W$ meridional gradient. In fact, Hsieh and Cook (2007) demonstrated that their RCM was able to handle the energetics of the AEJ-AEW system quite accurately. As can be inferred from Table 2 and Fig. 2k, RCA4 is the closest model to ERAI in representing the position and the amplitude of the baroclinic zone. In particular, the $30 \mathrm{~mm}$ contour of $P W$, which is the marker of the Inter Tropical Discontinuity (ITD) according to Bock et al. (2008), is quite well reproduced. The JJAS-mean precipitation of RCA4 is also consistent with the observations, except near the western coast, where it is overestimated 
with respect to ARC2. For instance, the mean rainfall and its south/north gradients (Table 2) at $0^{\circ}$ and $15^{\circ} \mathrm{E}$ are better simulated in RCA4 than in ERAI. Some similarities can be noted between RCA4 and CanRCM4, although the latter seems slightly wetter over $15-20^{\circ} \mathrm{N}$.

CCLM and RACMO22T present a relatively moister Sahel and a weaker $P W$ gradient than ERAI, and their seasonal-mean $P W$ is clearly overestimated between 10 and $20^{\circ} \mathrm{N}$, with all values above $40 \mathrm{~mm}$ (Fig. $2 \mathrm{~g}$, i). The Saharan Heat Low region (minimum of $P W$ north of $20^{\circ} \mathrm{N}$ in Fig. 1a) is almost nonexistent in the west or confined over Libya and Egypt in the east. Regarding the precipitation field, these RCMs simulate the precipitation patterns north of $17^{\circ} \mathrm{N}$ relatively well despite the fact that they overestimate $P W$. However, as shown by the $1 \mathrm{~mm} \mathrm{day}^{-1}$ contour as well as their maximum rain belt $\left(10-15^{\circ} \mathrm{N}\right)$, these 2 RCMs tend to have zonally symmetric behavior and so do not reproduce the variations shown in observations (i.e.
ARC2 in Fig. 1b). Note that a subset of these RCMs was assessed by Paeth et al. (2011) with similar remarks considering their biases in mean precipitation.

CRCM5 has quite singular behavior with an underestimation/overestimation of the average amount of rainfall over the northern/southern Sahel, leading to stronger humidity gradients around the $15^{\circ} \mathrm{N}$ band (Fig. 2d). For example, around $0^{\circ} \mathrm{E}, P W$ decreases by $\sim 31 \mathrm{~mm}$ from $10^{\circ} \mathrm{N}$ to $20^{\circ} \mathrm{N}$ in CRCM5, whereas in ERAI it decreases by $\sim 21 \mathrm{~mm}$ (Fig. $2 \mathrm{c}$ and a, respectively). This excessive gradient in CRCM5 appears to be related to its overestimated precipitation south of or near $10^{\circ} \mathrm{N}$, and almost no rainfall north of $15^{\circ} \mathrm{N}$. More generally, despite significant discrepancies with respect to ERAI $P W$, most of the RCMs tend to improve the spatial distribution of precipitation shown by ERAI over the whole Sahel area. It also seems clear that, when RCMs have a good representation of $P W$ (such as RCA4), they reproduce the seasonal-mean rainfall more accurately. (a) ERAI: JJAS $P W$

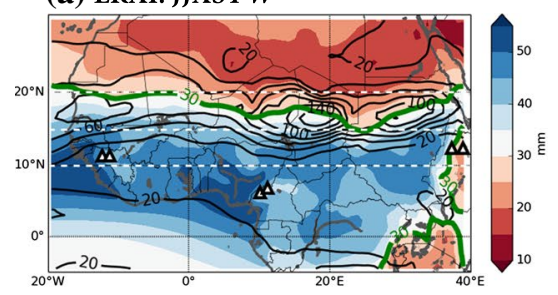

(b) ERAI: JJAS RR

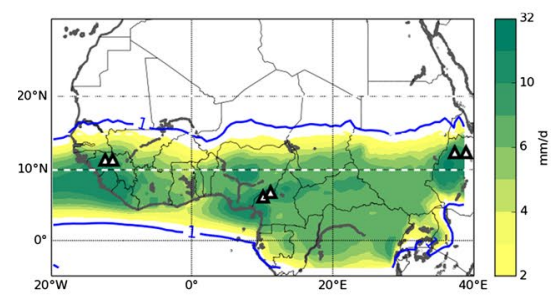

(g) CCLM: JJAS PW

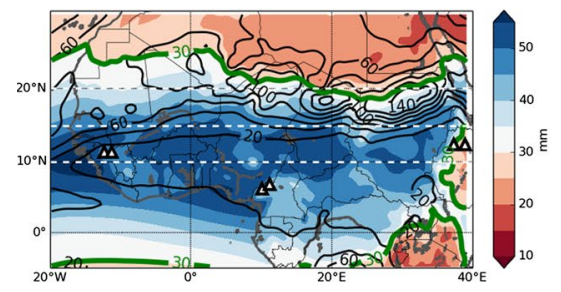

(h) CCLM: JJAS RR

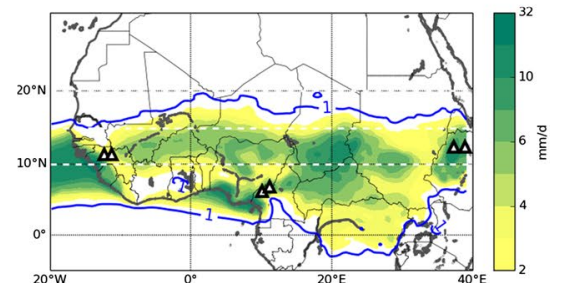

(c) CRCM5: JJAS PW

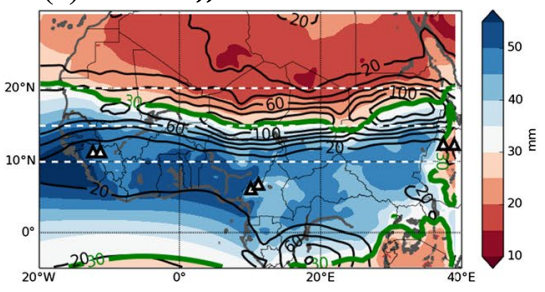

(d) CRCM5: JJAS RR

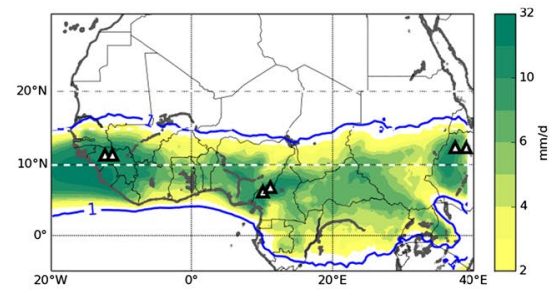

(i) RACMO22T: JJAS PW

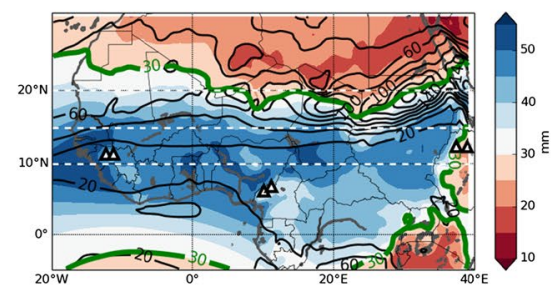

(j) RACMO22T: JJAS RR

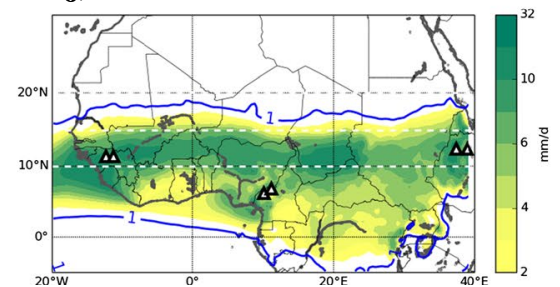

(e) CanRCM4: JJAS $P W$

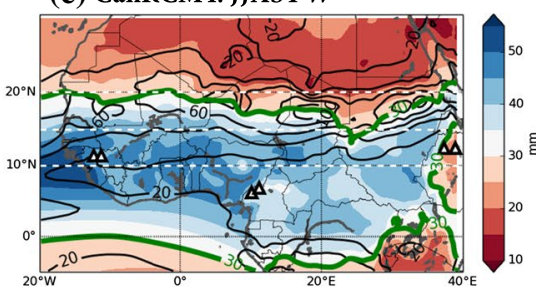

(f) CanRCM4: JJAS RR

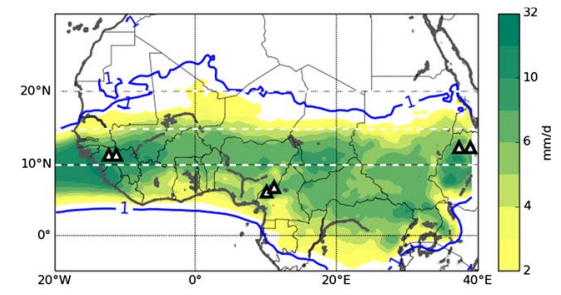

(k) RCA4: JJAS PW

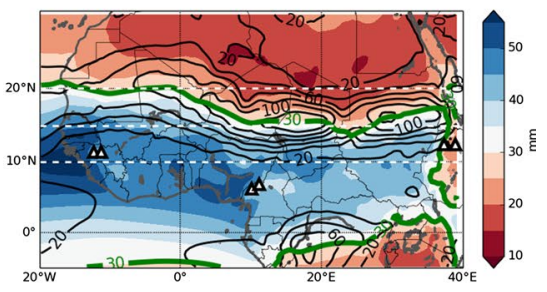

(l) RCA4: JJAS RR

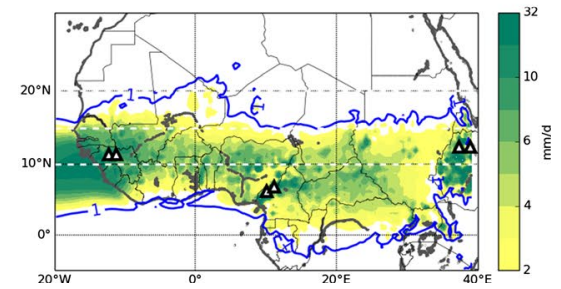

Fig. 2 Same as Fig. 1, but for ERAI and ERAI-driven RCMs, the names of which are given in the titles 


\section{WAM intraseasonal scales in RCMs}

In principle, regional modeling is expected to significantly improve the way general features of the WAM dynamics are represented and, in particular, its intraseasonal activity, such as onset-retreat, persistent dry-wet spells, and also AEWs with respect to coarse-scale driving fields. As the humidity field is one of the key (and limiting) factors for convection over the Sahel, $P W$ has been proposed by Poan et al. (2013) as an index to follow the WAM intraseasonal fluctuations as it can follow deep convective activity as well as low-level dynamics. This perspective is analyzed below with RCM simulations.

\subsection{Intraseasonality from the precipitable water perspective}

Figure 3 presents $P W$ variance filtered at two intraseasonal sub-scales: the 10-90-day band-pass and the 1-10-day high-pass, referred to hereafter as low- and high-frequency (or synoptic) scales, respectively. These two subscales were chosen in order to distinguish between monsoon activity due to meteorological phenomena, and its relatively slower (biweekly to monthly and seasonal) temporal variations that are more often related to broader time and space phenomena involving interactions with the two surrounding oceanic basins (Indian and Atlantic). ERAI variance displayed (a) ERAI: Var bp10-90

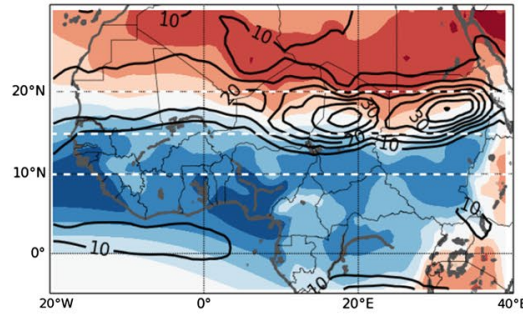

(b) ERAI: Var hp10

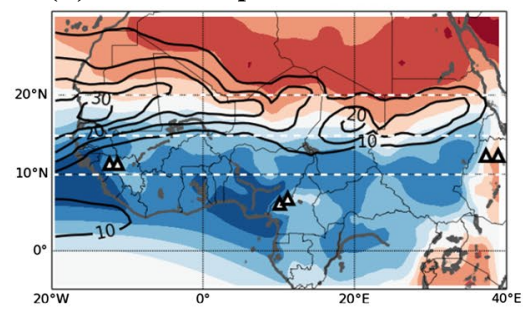

(g) CCLM: Var bp10-90

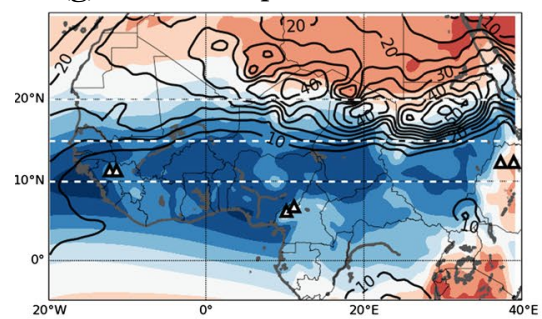

(h) CCLM: Var hp10

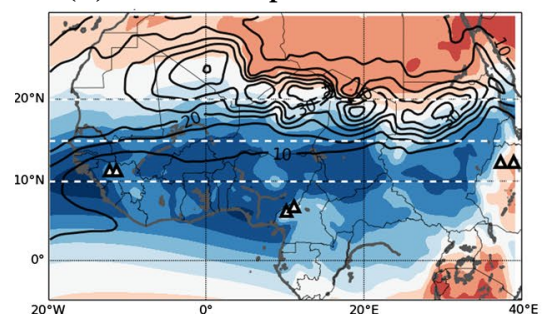

(c) CRCM5: Var bp10-90

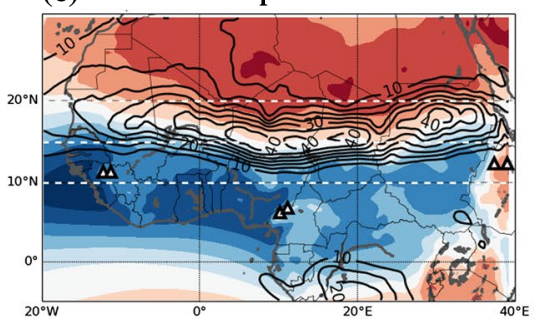

(d) CRCM5: Var hp10

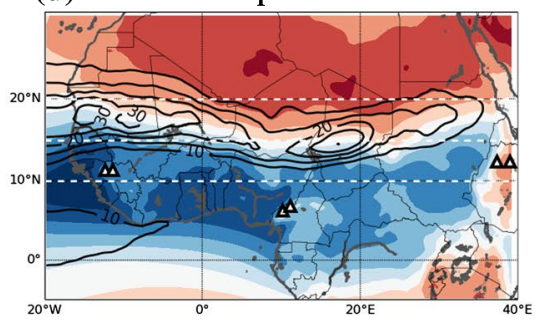

(i) RACMO22T: Var bp10-90

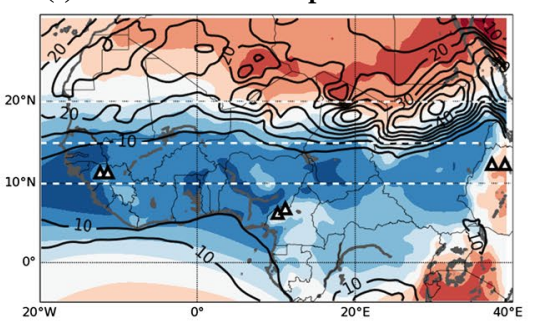

(j) RACMO22T: Var hp10

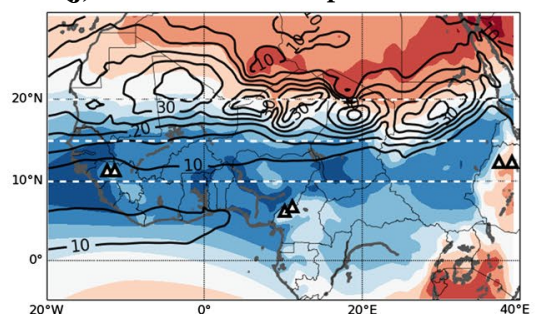

(e) CanRCM4: Var bp10-90

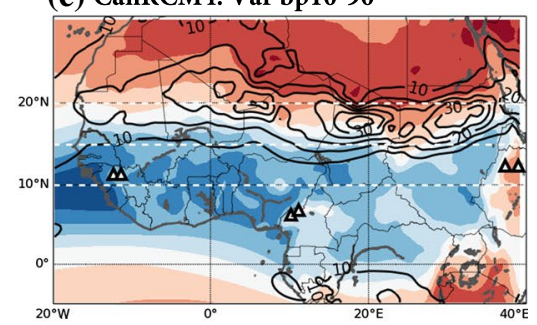

(f) CanRCM4: Var hp10

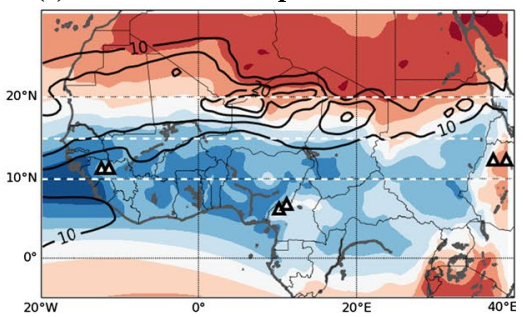

(k) RCA4: Var bp10-90

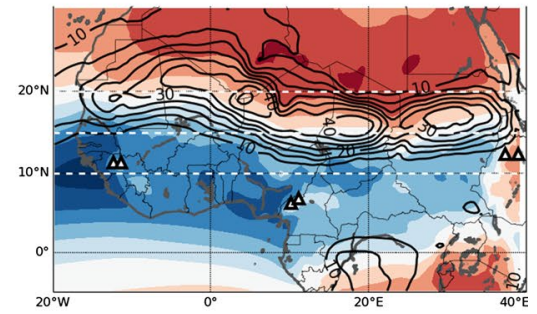

(l) RCA4: Var hp10

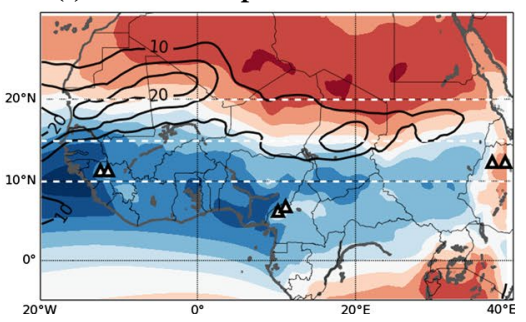

Fig. 3 1989-2008 JJAS $P W$ Intraseasonal variance partitioning (contours in $\mathrm{mm}^{2}$ ). For each pair of rows, the top panels show the 10-90day band-pass variance and the bottom panels the 10-day high-pass variance for each dataset, the names of which are given in the titles. The colors show the seasonal mean $P W$ (as in Fig. 2) 
in Fig. 3a, b has been discussed in Poan et al. (2013) and only some essential elements are recalled here for the comparison with the RCMs. Firstly, maximum variance in both frequencies is confined between $15^{\circ} \mathrm{N}$ and $25^{\circ} \mathrm{N}$ (similarly to the total variance shown in Fig. 2) with, however, quite a strong east-west asymmetry. As shown by Leroux et al. (2010), low-frequency variability is greater and mainly prevails over Eastern Africa, east of $10^{\circ} \mathrm{E}$ (Fig. 3a), then decreases westward from $15^{\circ} \mathrm{E}$. Conversely, the 1-10-day band (Fig. 3b), first weaker east of $20^{\circ} \mathrm{E}$, rapidly becomes predominant further west, reaching a maximum over the west coast. This 1-10-day variance structure is consistent with the well-known pattern of AEWs, which are triggered over the eastern mountains and then grow quickly on the mean-state baroclinic energy as they propagate westward (Burpee 1972).

As for ERAI, the RCM intraseasonal variance reproduces the overall pattern of the mean JJAS variance, confining the highest values along the strong gradient zone. Considering more specifically the distribution within the two frequency bands, most of RCM simulations seem rather inaccurate in comparison with the reanalysis. First, the large Eastern African low-frequency activity shown in all RCMs simulations (variance field in 10-90-day) is consistent with the analysis of Alaka and Maloney (2012) showing that the MJO dry and wet phase oscillations induce strong $P W$ fluctuations over this region. Although this MJO-like behavior seems fairly consistent with ERAI fields and the findings of Alaka and Maloney (2012) east of $10^{\circ} \mathrm{E}$ - Central to Eastern Africa, the low-frequency activity appears to be overestimated in all RCMs over the rest of the continental Sahel. This is reminiscent of some results on the WAM intraseasonal-scale analysis with CMIP5 GCMs by Roehrig et al. (2013) and implies that, even in RCMs, there is still an overrepresentation of the impacts of larger-scale phenomena (from oceanic basins, tropical waves such as MJO). Regarding the 1-10-day variability, only two RCMs (RCA4 in Fig. 3k-1 and CRCM5 in Fig. 3c, d) are able to reproduce the zonally westward growth structure of the $P W$ variance. In fact, except for these two models, there is no clear distinction in the intraseasonal variance distribution between the two sub-scales. For instance, CCLM (Fig. 3g, h) and RACMO22T (Fig. 3i, j) display structures that are almost analogous for the two frequency bands, concentrating the variance east of the Greenwich meridian, with a northward shift of the variance field. Therefore, the westward increase in synoptic variability is not well reproduced, implying that these RCMs might not be efficient to handle AEW dynamics or their relative contribution to the intraseasonal (rainfall) variability. As discussed in the introduction, numerous studies have illustrated RCMs' ability to represent the dynamics of AEWs, but without any clear links to the Eastern region activity that, at least partly, controls AEW intermittency (e.g. Mekonnen et al. 2006; Leroux et al. 2010). From this $P W$ perspective (which may be verified with another dynamical field), it appears that the eastern low-frequency/western high-frequency connection remains a weakness for current RCM simulations (but to a lesser extent for RCA4 and CRCM5).

Figure 4 summarizes, in two regional sub-domains identified as coastal $\left[20^{\circ} \mathrm{W}-10^{\circ} \mathrm{W} ; 12-20^{\circ} \mathrm{N}\right]$ and continental $\left[5^{\circ} \mathrm{W}-5^{\circ} \mathrm{E} ; 12-20^{\circ} \mathrm{N}\right]$, the $P W$ "total" intraseasonal variance (hp90 variance) and the previously discussed variance divided in two frequency bands. For each model (combining RCMs driven by ERAI and by GCMs), "total" variance normalized by ERAI one is shown, while the two frequency bands are analyzed in terms of relative contributions to their sum. For example, over the coastal region, CRCM5 driven by ERAI has approximately the same variance as ERAI ( $103 \%$ of ERAI variance): $42 \%$ of this intraseasonal variance is due to low-frequency activity while the rest $(\sim 58 \%)$ is due to synoptic scales. This sub-scale partitioning stays close to the ERAI one for most RCMs over the western coast. However, the inter-model spread in terms of total $P W$ variance among RCMs is more substantial over the central WAM region (i.e. $5^{\circ} \mathrm{W}-5^{\circ} \mathrm{E}$ ). This is especially the case when RCMs are driven by GCMs instead of ERAI, especially for the two Canadian RCMs (not shown). Hence, the lateral boundary conditions appear to have significant effects on the "total" intraseasonal variance for the two Canadian RCMs over the central WAM area, with quite a large overestimation of the total $P W$ variance when CRCM5 and CanRCM4 are driven by the CanESM2 model. This sensitivity of the intraseasonal variability to the boundary conditions has been also noted in Pohl and Douville (2011), but contrasts with the conclusions of Sylla et al. (2009) who found that GCM biases (or boundary conditions) had quite a small impact on RCM performance.

Regarding the partitioning of this variance into the two frequency bands, the reference ERAI shows the predominance of the synoptic scales in both regions, with a growing fraction as the transient structures propagate westward. As discussed above, the majority of RCMs encounter difficulty in reproducing this behavior according to the chosen region. For example, although CRCM5 simulates the distribution quite similarly to reanalysis over the coast (as illustrated by the ratios), the differences with ERAI increase over the continent. In addition, it should be noted that, although CRCM5, RCA4 and, to a lesser extent, CanRCM4 reproduce the synoptic variance structure quite well (as shown in Fig. 3), they display an inaccurate ratio over the continental area (as shown in Fig. 4) due mainly to an overestimation of the low-frequency variability ( $>10$ days) over the central and western Sahel. This has the effect of increasing longer timescale phenomena at the expense of meteorological events or high-frequency variability. 


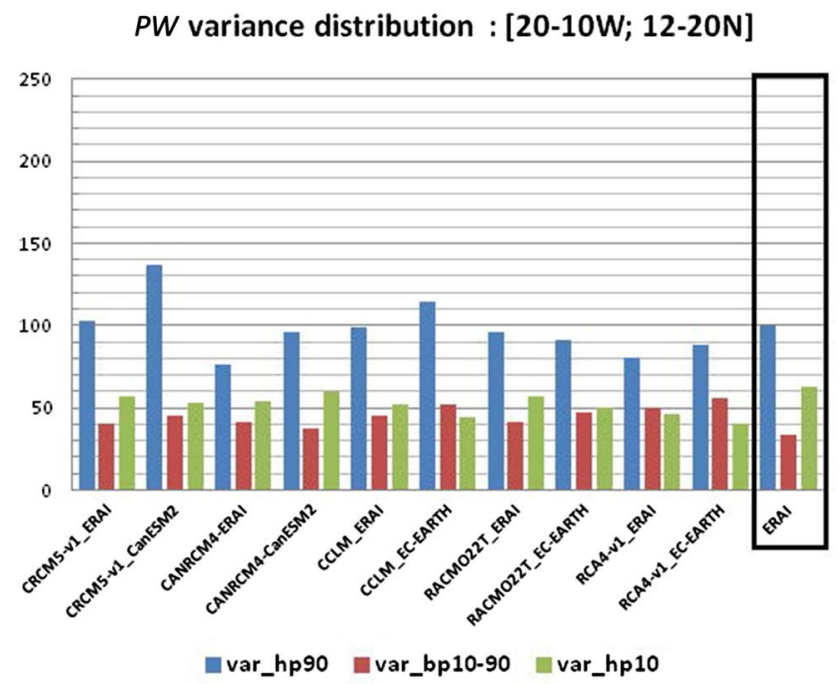

Fig. 4 Regional average of $P W$ intraseasonal variance distribution across different time scales over JJAS for 1989-2005: the "total intraseasonal scale" as 90-day high-pass variance (var_hp90 in blue), the "low frequency scale" as 10-90-day band-pass variance (var_bp10-90 in red) and the "high frequency scale" as 10-day high-pass variance (var_hp10 in green), for the coastal $\left[20^{\circ} \mathrm{W}-10^{\circ} \mathrm{W}, 12-20^{\circ} \mathrm{N}\right]$ and the

Reducing the proportion of low-frequency variability is therefore a challenge that must be met by most RCMs and, by extension, by GCMs as already shown by Roehrig et al. (2013), if they are to better represent scale interactions crucial for AEW triggering, development and intermittency (Leroux et al. 2010).

\subsection{Intraseasonality from the precipitation perspective}

\subsubsection{Illustration with the 2009 season: wavelet analysis}

To illustrate the WAM intraseasonal activity in terms of precipitation, Fig. 5 displays the rainfall time series and their corresponding wavelet spectrum during the year 2009. We focus on the region $\left[5^{\circ} \mathrm{W}-0^{\circ} \mathrm{E} ; 10-15^{\circ} \mathrm{N}\right]$ (in Burkina Faso, including Ouagadougou) and the 2009 season, as this year was abnormally humid, with a devastating flood (more than $200 \mathrm{~mm} /$ day) that occurred on 1st September 2009, the wettest day at Ouagadougou for more than 90 years (BBC News 2009). Galvin (2010) has documented this meteorological event and shown that it was associated with two successive, strong AEWs within which intense MCSs occurred. This case study allows us to evaluate how RCMs (in reanalysis-driven mode) can represent the intraseasonal variability of the WAM and, more specifically, when extreme events occur within the season. The time series (top panel) show the daily precipitation and its anomalies over the year 2009. The wavelets (bottom panel) represent the time series (on $\mathrm{X}$-axis) of
$P W$ variance distribution : [5W-5E; $12-20 \mathrm{~N}]$

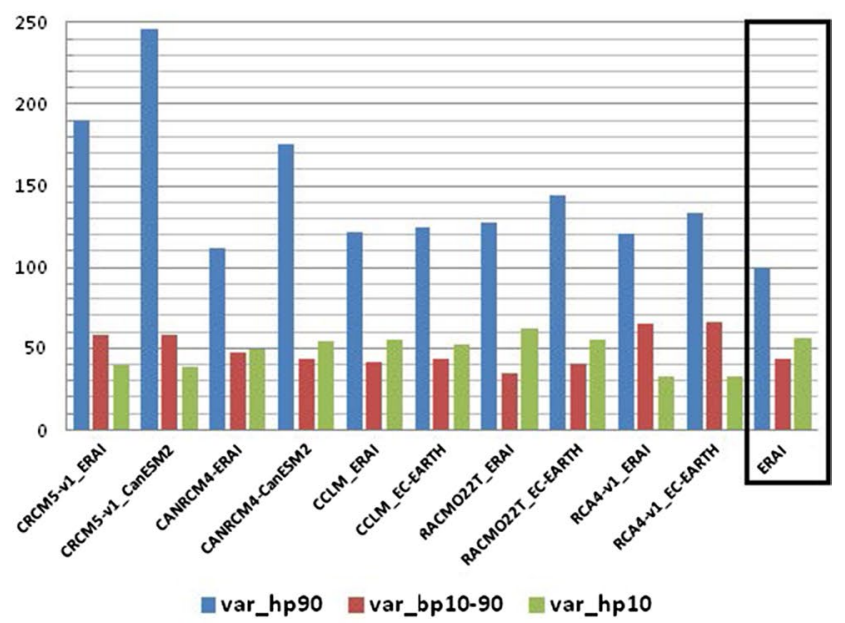

continental $\left[5^{\circ} \mathrm{W}-5^{\circ} \mathrm{E}, 12-20^{\circ} \mathrm{N}\right]$ regions. The var_hp90 bars represent the ratio (\%) of each simulation variance relatively to that of ERAI, while the $h p 10$ and the bp10-90 bars represent for each simulation, the ratio relatively the "total" intraseasonal variance within each simulation. Note that two GCM-driven simulations are also represented

the precipitation variance (in color scale, in $\mathrm{mm}^{2}$ days ${ }^{-2}$ ) for each time scale ( 2 to 90 days on Y-axis). The vertical blue (red) dashed line represents the average date of local onset (retreat), computed following the method described in Sect. 2.3 and averaged over the domain. The first top panels from the three observed datasets reveal quite similar results for both precipitation time series and wavelet spectrum. The time series imply that a large amount of the rainfall variability is ascribable to the intraseasonal fluctuations (red curve). The monsoon onset (blue dashed line) occurs around early June and is consistent with the beginning of persistent rainfall or wet spells (i.e. duration and intensity of regular precipitation events). A small difference between observations comes from ARC2 data (Fig. 5b) (the higher resolution dataset), which shows an onset earlier by about 2 weeks and a later retreat than TRMM and GPCP. The three intraseasonal scales of the WAM discussed previously can be seen quite distinctly in the wavelet spectrum, with the energy decreasing progressively from the synoptic scale (less than 10-day fluctuations), through the 10-25 day to the 30-90-day bands. Isolated rainy events start in late May-early June, as the atmosphere becomes increasingly humid. Then, more regular and intense events take place between June and August, after which comes an important decrease in the intraseasonal activity, signaling the monsoon retreat. The flooding event of later August-early September (around day 240) can be seen in all the observational datasets. Even though a remarkable intensity is visible around day 240 at synoptic scale, there is also a 
(a) TRMM

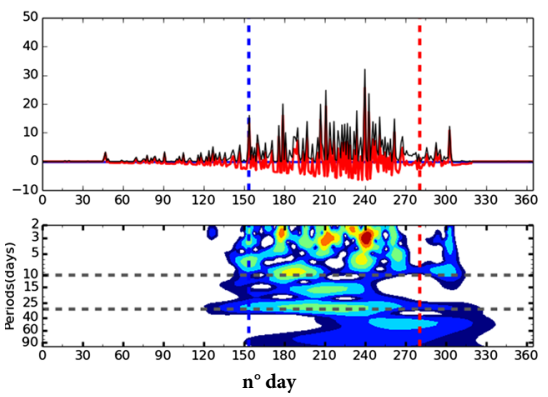

(d) ERAI

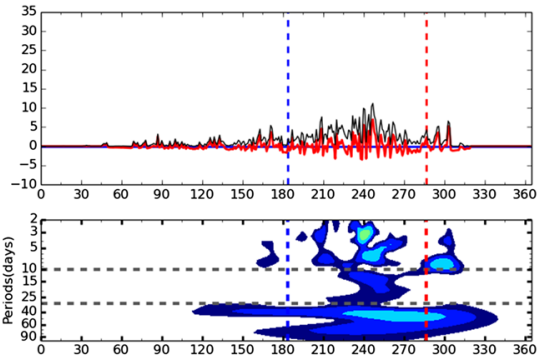

(g) RCA4

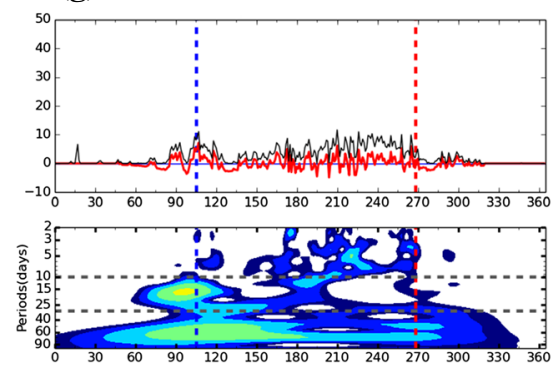

(b) ARC2

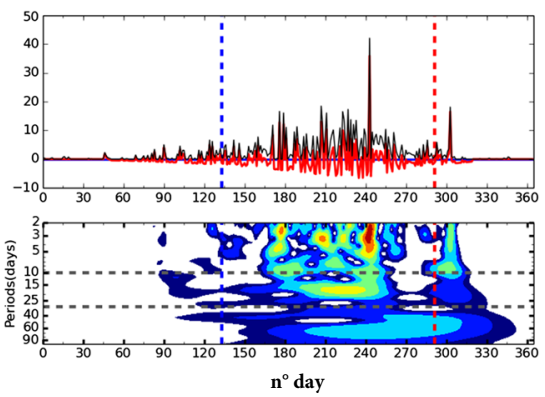

(e) CRCM5

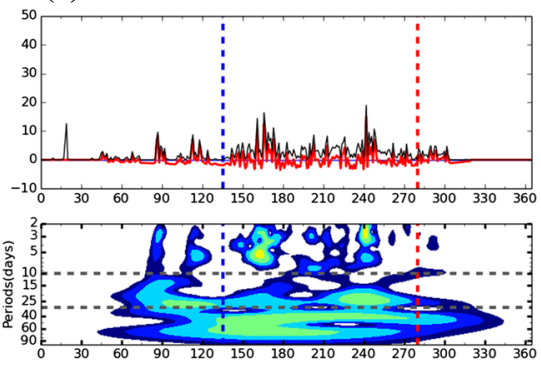

(h) HIRHAM5

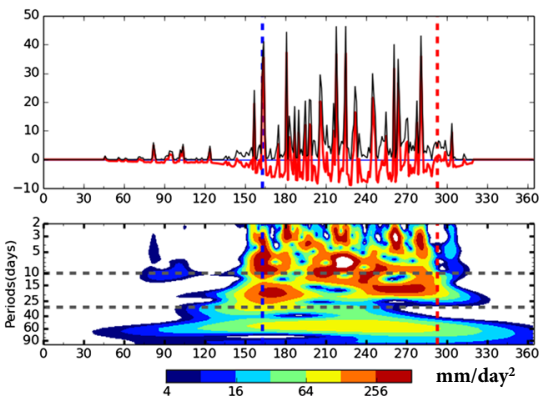

(c) GPCP

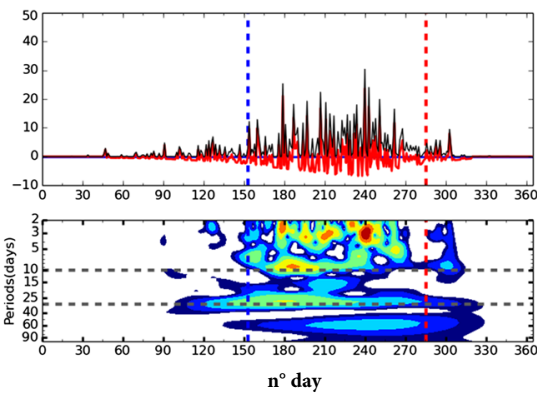

(f) CanRCM4

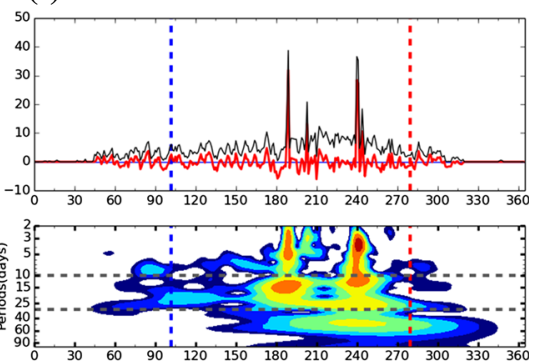

(i) RACMO22T

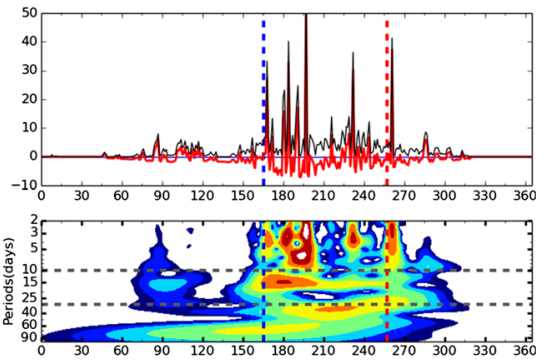

Fig. 5 Overview of the monsoon season 2009 across the Burkina Faso region $\left[10-15^{\circ} \mathrm{N} ; 5^{\circ} \mathrm{W}-0^{\circ} \mathrm{E}\right]$ from TRMM, ARC2, GPCP, ERAI and ERAI-driven RCMs. For each pair of panels, the top plot curves represent daily precipitation time series (in black, $\mathrm{mm} \mathrm{day}^{-1}$ ) and their intraseasonal anomalies as 90-day high-pass filtered (in red).
The bottom panels give the wavelet daily rainfall variance spectrum in $\mathrm{mm}^{2}$ day $^{-2}$ computed from the intraseasonal anomalies. The vertical blue (red) line represents the date of the onset (retreat) in day of year (ranked between 1 and 365) for each dataset mentioned in the title

day 240) is quite weak. The RCM simulations generally improve the variability in time series as well as the onset-retreat timing and, except for RCA4 (Fig. 5j), they capture the intense precipitation event that occurred near day 240 , and that caused the flooding episode, quite well. The wavelets computed on RCM simulations, as opposed to ERAI, reveal a more intense synoptic-scale activity (below 10 days), more often after June, and so seem more consistent with observations. Differences among RCMs and the three observational datasets appear mainly in the low frequencies, where RCMs generally overestimate the variability, especially above 25 days. Figure 5 also shows that a majority of RCMs simulate an onset that is too early, except from HIRHAM5 and RACMO22T, which tend to show a later onset. 
The use of three different versions of CanRCM4 (not shown) reveals that, more than resolution or dynamical spectral nudging, the physical parameterization has a greater role to play in the intraseasonal monsoon variability and in its modulation at various timescales over the continental Sahel area. This is consistent with the findings of Flaounas et al. (2011), who showed drastic changes depending on the physical parameterizations.

\subsubsection{Precipitation frequency spectrum analysis}

After the illustration of season 2009, the following analysis (Fig. 6) aims to give a climatological view of the WAM precipitation intraseasonal spectrum. Normalized power spectrum densities (PSDs), computed over 1989-2008 for each RCM and for the two previously discussed sub-regions, are therefore displayed in Fig. 6. On each panel, ERAI (red) and ARC2 (blue) corresponding PSDs are superimposed so that comparisons can be made.

It is interesting to compare the PSDs from ARC2 and ERAI by considering just the blue and red curves on Fig. 6a. Over the continent (right), the ARC2 spectrum (blue) shows the separation between the synoptic scales and the low frequencies distinctly. The low frequencies peak around 40-30 days, consistently with the MJO energy peak. This scale was described by Matthews (2004) as a remote response to the intraseasonal activity over the warm pool. Over the continent, an important role is played by scales shorter than 10 days. These scales are associated with the activity of AEWs, which have been classified in two typical time periods: 6-9 days (Diedhiou et al. 1999) and 2-5 days (Reed et al. 1977). The coastal region spectrum has a quite different structure and does not show a noticeable separation between the two scales. The synoptic-scale energy peaks between 6 and 3 days, and then tends to decrease sharply, unlike the continental one. This implies that convection occurs on relatively longer time scales at the coast, while it is more intermittent or sporadic over land. Finally, it is worth mentioning that both TRMM and GPCP spectra, computed over the same regions (not shown), present the same scale patterns as the ARC2 spectrum.

The spectrum of ERAI displays a flat maximum from the lowest frequencies (90 day period) up to the 10-day period. It is apparently unable to distinguish the MJOlinked activity and the 10-25-day period fluctuations. This plateau is also consistent with the wavelet analysis of the 2009 season, where most of the variability arises at longer time scales. At synoptic scales, the spectrum peaks around a 7-5-day period and this can be related to an AEW-like mode, even though that period range is higher than what is generally expected. The contribution of scales shorter than 5 days is significantly reduced compared with observations. This PSD analysis therefore confirms, as could be inferred from the 2009 wavelet analysis, that ERAI experiences strong difficulties in representing the occurrence and, above all, the intensity of synoptic to mesoscale systems over the Sahel. That might be why it shows large dry biases at these latitudes (Nikulin et al. 2012).

The general picture of all RCM PSDs (see Fig. 11 in the Appendix) shows an "ERAI-like behavior" marked by a non-realistic excess of the low-frequency variability, especially over the continent. The intraseasonal maximum variability around 30-40-day in the observations is not significantly or distinctly reproduced by the RCMs. RACMO (Fig. 6c), CCLM (Fig. 6d) and HIRHAM5 (Fig. 6f) realistically improve the PSD for both regions even though the tail of the spectrum (higher frequencies) is weaker. Some RCMs show a strong regional sensitivity by improving the PSD for one region while degrading it for another. For instance, CRCM5 in Fig. 6a shows, on the one hand, a remarkably ARC2-like PSD over the coast (left) and, on the other hand, a particularly misrepresented PSD over the continent. Finally, RCA4 (Fig. 6e) exacerbates the imbalance of the low-frequency to high-frequency ratio, consistently with its wavelet representation in Fig. $5 \mathrm{~g}$.

A quantitative assessment of the African monsoon rainfall variability is shown in Fig. 7 with the intraseasonal partitioning (10-90 day, 3-10 day, 1-3 day in Fig. 7b) of the daily precipitation over the continental and coastal regions, from ERAI-driven RCM simulations, ERAI and observations. The climatological mean for each region is represented in Fig. 7a. First, the three observations are quite similar regarding both JJAS-mean rainfall and their intraseasonal variance distribution. The synoptic scales (i.e. 3-10 day and 1-3 day, by order of importance) explain more than $80 \%$ of the precipitation intraseasonal variability, consistently with the conclusions of Mathon et al. (2002) on the influence of MCSs on the seasonal rainfall amount. The highest frequency (1-3-day period) is almost twice as important as the lowest frequency (10-90-day period) whatever the region.

Regarding the RCMs, the large dispersion of JJAS average among models (Fig. 7a) is closely related to the inaccurate partitioning of the intraseasonal variability between the lowest (10-90-day period) and the highest frequency (1-3day period), with rather accurate values for intermediate frequency (i.e. 3-10-day period). Some studies (e.g. Sylla et al. 2010; Mariotti et al. 2014) have highlighted the ability of RCMs to represent AEWs based on 700-600 hPa, 3-10day filtered meridional wind fluctuations. Our analysis reveals that, in terms of precipitation activity, this scale is not the most critical for RCMs. In fact, the models mainly underestimate the highest frequency (1-3 day period) and conversely overestimate the lowest (10-90-day) one, and their respective contributions to the precipitation variance. This is also the case for the ERAI products. However, this 

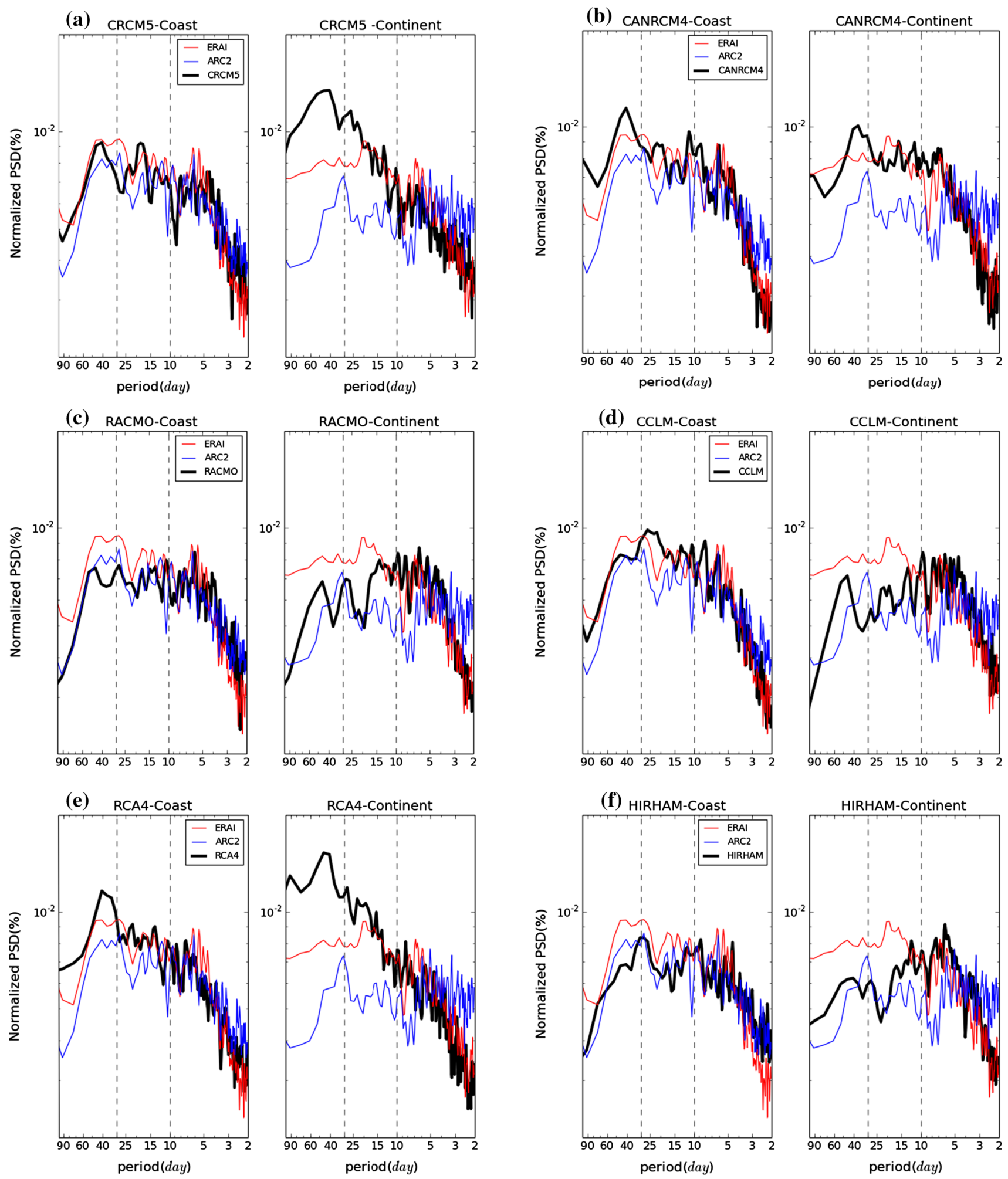

Fig. 6 1989-2008 JJAS average of daily rainfall normalized power spectral density (PSD), for ARC2, ERAI and each ERAI-driven RCM, averaged over two regions of the Sahel: the coastal region
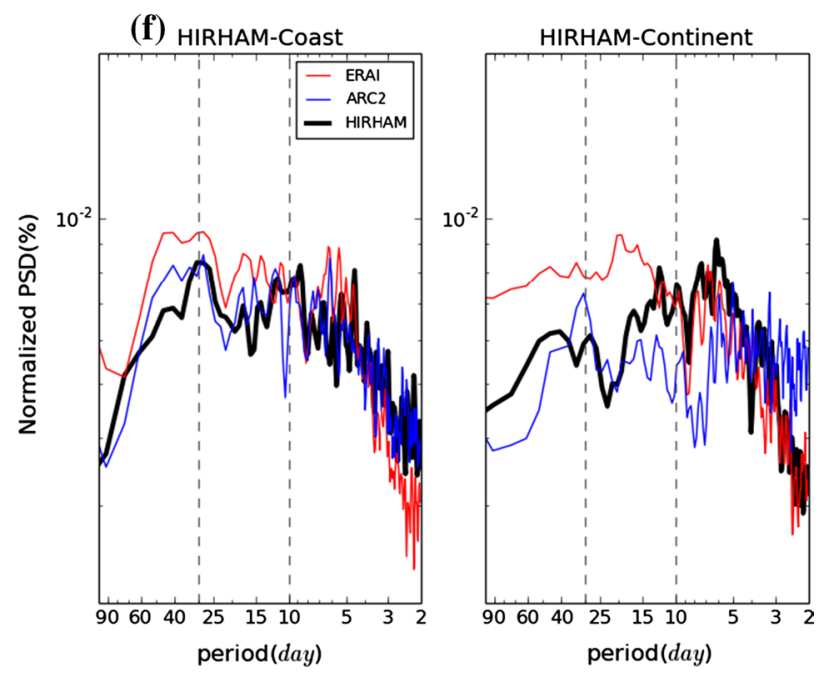

$\left[20^{\circ} \mathrm{W}-10^{\circ} \mathrm{W} ; 12^{\circ} \mathrm{N}-17^{\circ} \mathrm{N}\right]$ (left) and the continental region $\left[5^{\circ} \mathrm{W}-\right.$ $\left.5^{\circ} \mathrm{E} ; 12^{\circ} \mathrm{N}-17^{\circ} \mathrm{N}\right]$. The normalization was performed with respect to the total intraseasonal variance in each box and for each dataset 
(a) JJAS Mean RR: [20-10W; 12-17N]

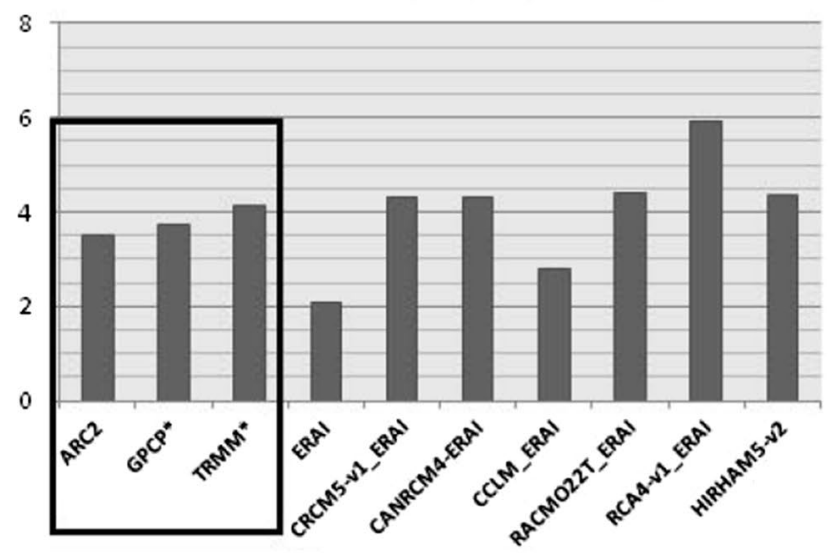

(b) RR variance distribution : [20-10W; 12-17N]

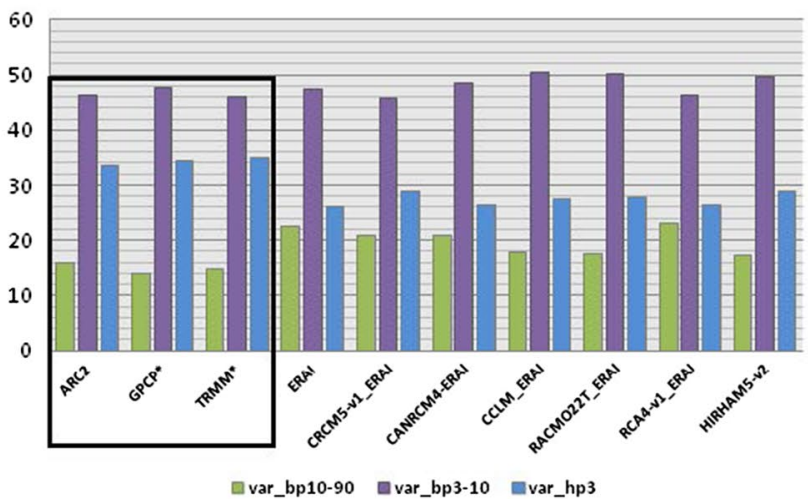

Fig. 7 1989-2008 JJAS mean precipitation (top, in $\mathrm{mm} \mathrm{day}^{-1}$ ) and its intraseasonal variance ratio (bottom, in \%) split into three subscales: 10-90-day band-pass (green), 3-10-day band-pass (purple),

partitioning among various time scales is slightly better reproduced over the coastal area than over the interior of the Sahel area for the majority of RCMs (except ERAI). Consequently, their JJAS mean rainfall shows better agreement with the observations over the western WAM region than over the continental area. The assessment of such aspects in GCMs by Roehrig et al. (2013) has shown a more exacerbated tendency of GCMs to overestimate (underestimate) low (high) frequencies.

\section{WAM onset/retreat and daily precipitation indices}

This section aims to evaluate some specific aspects of the WAM intraseasonal variability, namely its onset/retreat and the resulting precipitation indices related to the occurrence, duration and intensity of daily events during the monsoon season. The day-to-day rainfall activity and its analysis are of crucial importance, not only for economic activity
JJAS Mean RR: [ 5W-5E; $12-17 \mathrm{~N}$ ]

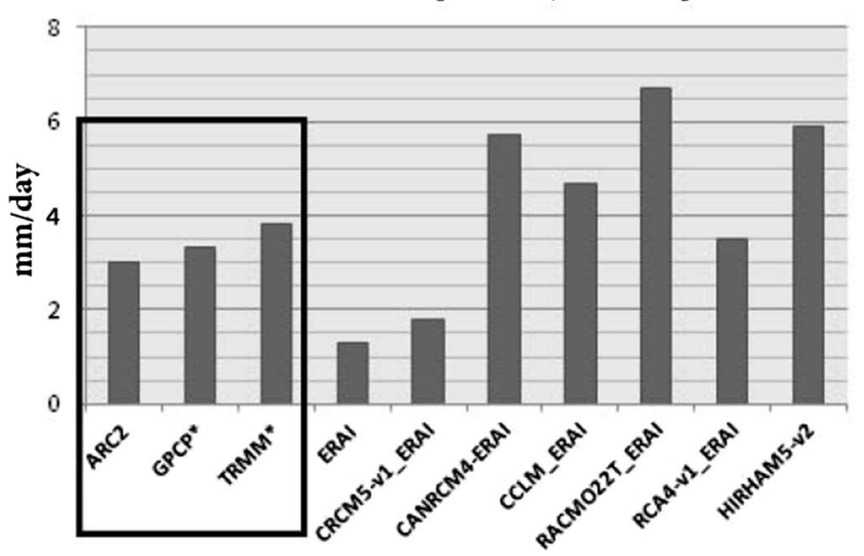

RR variance distribution : [5W-5E; $12-17 \mathrm{~N}]$

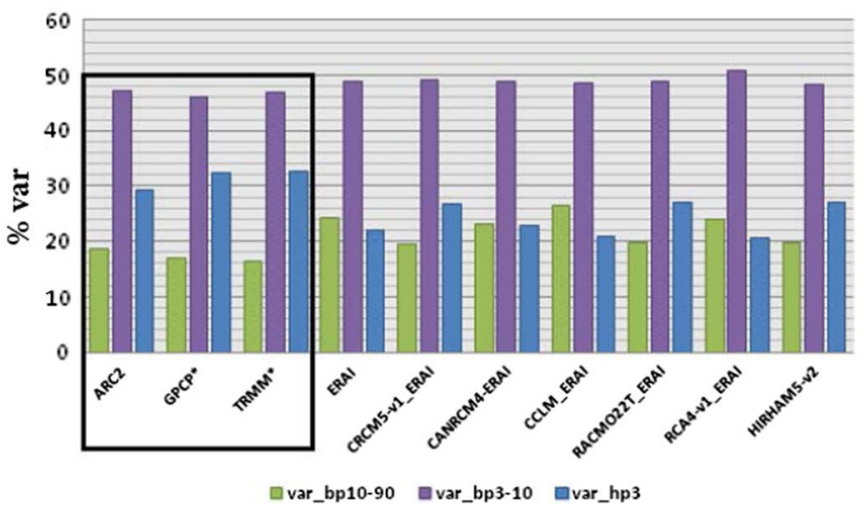

and 3-day high-pass (blue). GPCP and TRMM data correspond to the 1998-2008 period

throughout the Sahel, but also because this complements the analysis of the partitioning of low and high frequencies in the mean daily rainfall. There is a straightforward relationship between a model's ability to handle the intraseasonal spectrum and its performance regarding the daily precipitation statistics that account for the occurrence of events (e.g. onset/retreat and wet/dry days), their duration and their intensity (e.g. dry/wet spells and high quantiles). Thus, this section is used to propose a more precise quantification of how RCMs improve (or not) the intraseasonality of the WAM with respect to their driving boundary conditions.

\subsection{Monsoon climatological local onset-retreat}

As discussed in the methodology section, the onset-retreat is computed locally, at each grid point, following Diaconescu et al. (2015). Figure 8 presents the climatological local onset over the Sahel region from ARC2, ERAI and the six RCMs driven by ERAI. The onset patterns from 
(a) ARC2

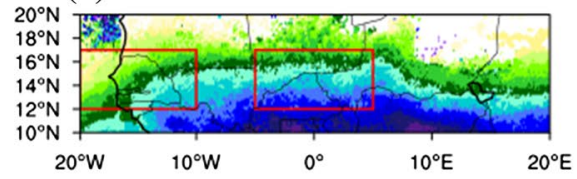

(c) CanRCM4

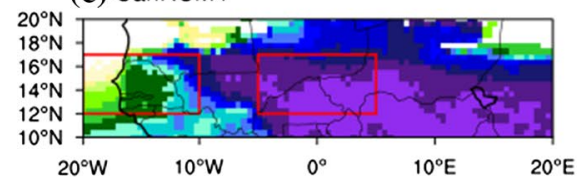

(f) RCA4
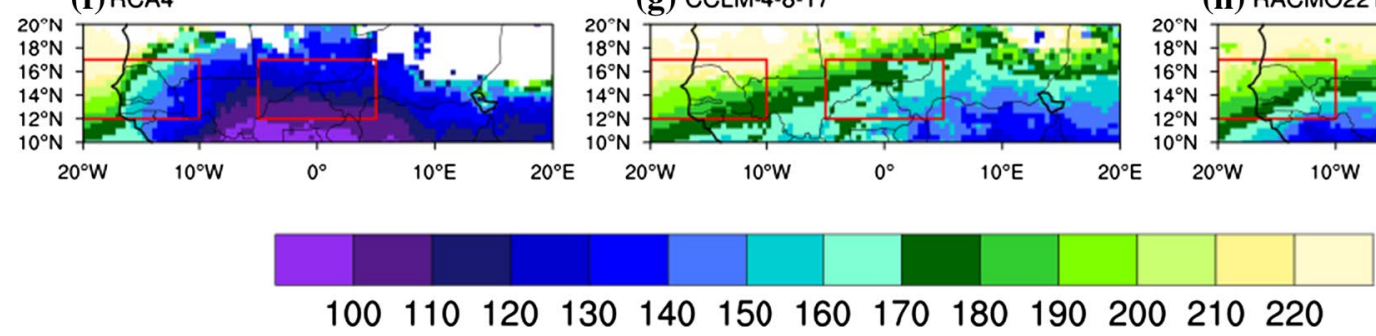

(b) ERAI

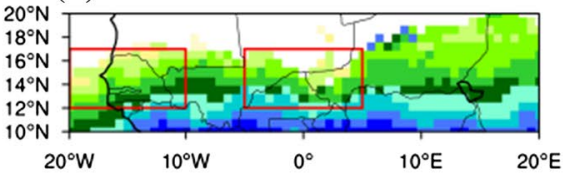

(e) HIRHAM5

(d) $\mathrm{CRCM} 5$

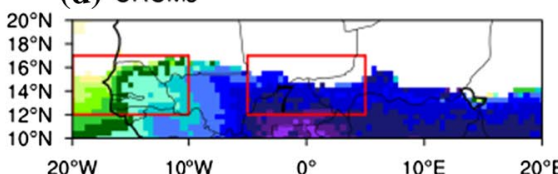

(g) CCLM-4-8-17

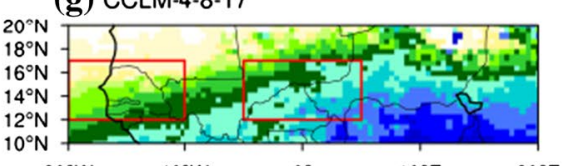

(h) RACMO22T
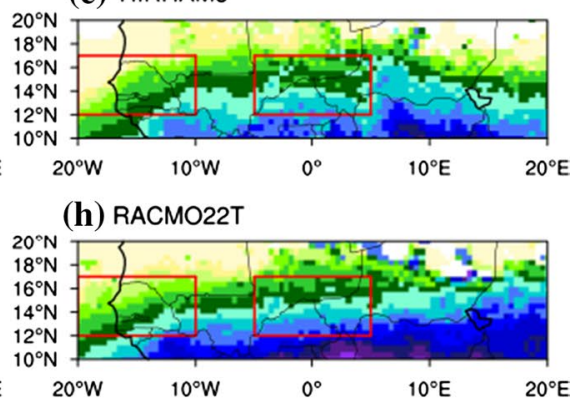

$20^{\circ} \mathrm{E}$

$20^{\circ} \mathrm{W}$

of year) for $\mathrm{ARC}$

2, ERAI and ERAI-driven RCMs. The two red boxes Fig. 8 Climatological (1989-2008) local onset
delimit the continental and the coastal regions

ARC2 recall the meridional structure of WAM precipitation. The first long-lasting rainy events start in early May (day 120) at around $10^{\circ} \mathrm{N}$, then progressively move northward, leading to an onset in late June - early July at latitudes around $15^{\circ} \mathrm{N}$. The date of onset occurrence is not zonally symmetric. In fact, east of $5^{\circ} \mathrm{E}$, onset is delayed by about 2-3 weeks (for a given latitude) between $10^{\circ} \mathrm{N}$ and $16^{\circ} \mathrm{N}$, with no onset occurring farther north around these longitudes. As highlighted by the seasonal-mean rainfall fields, ERAI also misrepresents the meridional structure of the onset over both coastal and continental areas. In fact, the onset is clearly delayed by at least one to three weeks over the Sahel area west of $5^{\circ} \mathrm{E}$. Conversely, over central Africa (or east of $5^{\circ} \mathrm{E}$ ), ERAI onset is too far north compared to ARC2, as eastern Niger and the greater part of Chad are areas where rainfall is known to be scarce, with a reduction in the occurrence of wet days and a delay in the onset over the $12-15^{\circ} \mathrm{N}$ bands in western Chad, and early onset in eastern Chad (Gachon et al. 2007).

The opposite (and unrealistic) behavior of onset over the continent given by the two Canadian RCMs (CRCM5 and CanRCM4) and RCA4 highlights the difficulty of simulating both the right date and the right location of the onset over the continental Sahel area (Fig. 8c, d). For example, the CRCM5 onset appears too far south (even farther south than in ERAI) while CanRCM4 is too far north. Also, both RCMs have some difficulties representing the latitudinal gradient of rainfall installation over most continental areas. Over the coastal region, however, they represent the patterns quite well, especially CRCM5 which is quite similar to ARC2. RCA4, despite its successful simulation of the seasonal-mean precipitation (at least over the continent), also misrepresents the meridional structure of the onset associated with rainfall patterns. However, it is worth noting its particularly good skill over the coastal region.

The other three RCMs perform quite well in general for the onset occurrence over the western Sahel. East of $5^{\circ} \mathrm{E}$, however, they experience difficulties in simulating the onset dates obtained by observations. HIRHAM5, CCLM and RACMO handle the onset latitudinal variation pretty well, especially over the continental area, and have also shown a distinguishable intraseasonal power density spectrum (PSDs in Fig. 6). Unlike CanRCM4, CRCM5 and RCA4, they capture the higher energy better at synoptic scales (AEW and MCS activity). Thus, this analysis reinforces the importance of the day-to-day activity and the so-called meteorological scales for longer scale patterns such as the WAM onset. Some analyses with RCMs driven by GCMs (Fig. 12) reveal a notably smaller impact of the driver. This may lend support to conclusions by Crétat et al. (2013) that physical parameterizations are crucial if RCMs are to handle the day-to-day rainfall variability and by extension the onset. As also suggested by Flaounas et al. (2012), larger scale dynamics, such as the Indian monsoon, also control the WAM onset and, therefore, the skill of RCMs should improve if the driving GCMs handle these large-scale dynamics correctly.

Along with the onset, the monsoon rainfall retreat is also an intraseasonal event of interest, as it also controls the length of the rainy season. In fact, for agricultural 
(a) ARC2

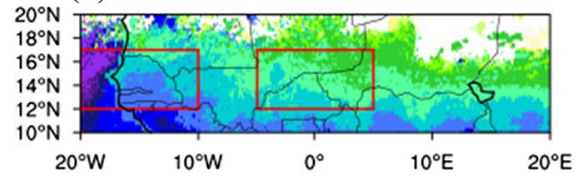

(c) CanRCM4

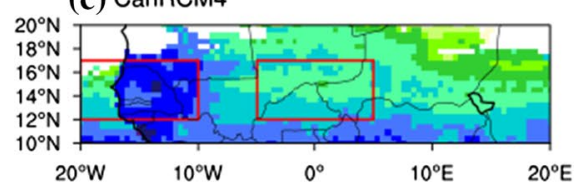

(f) RCA4
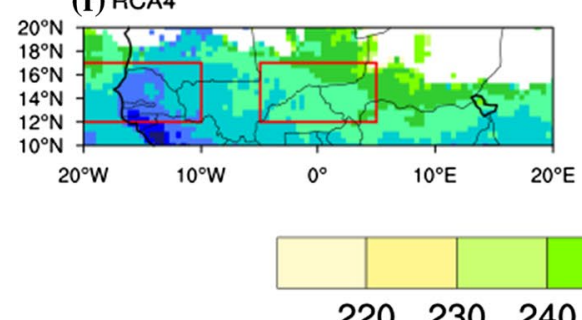

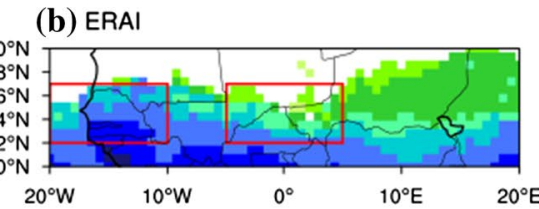

(d) CRCM5

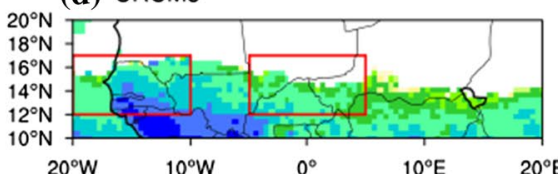

(g) CCLM-4-8-17

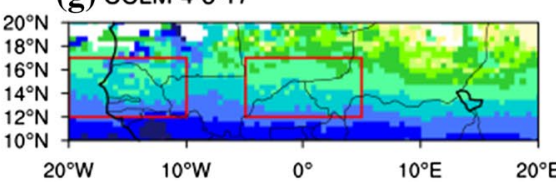

(e) HIRHAM5

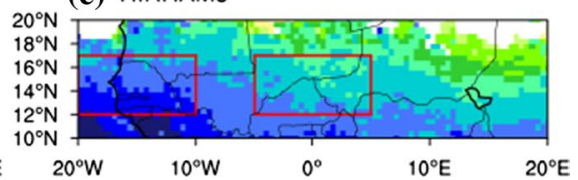

(h) RACMO22T

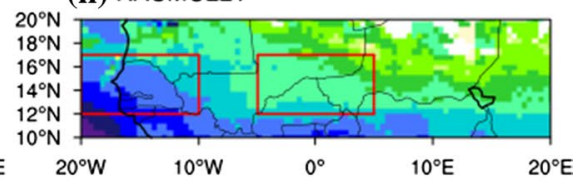

$\begin{array}{lllllllllll}220 & 230 & 240 & 250 & 260 & 270 & 280 & 290 & 300 & 310 & 320\end{array}$

Fig. 9 Same as Fig. 8, but for local retreat date

Table 3 Summary of the precipitation indices used to evaluate RCMs

\begin{tabular}{|c|c|c|}
\hline Index and description & Formula & Unit \\
\hline RMean: seasonal mean daily precipitation & JJAS mean precipitation & $\mathrm{mm} \mathrm{day}^{-1}$ \\
\hline R1mm: number of wet days & Fraction of days with precipitation $\geq 1 \mathrm{~mm}$ & $\%$ \\
\hline SDII: simple daily intensity index & Mean precipitation over wet days (with $\mathrm{PR} \geq 1 \mathrm{~mm}$ ) & $\mathrm{mm}$ day $^{-1}$ \\
\hline R20mm: heavy precipitation days & Percentage over JJAS of days with $\mathrm{PR} \geq 20 \mathrm{~mm}$ & $\%$ \\
\hline $\begin{array}{l}\text { Rd3: maximum amount of precipitation during } 3 \\
\text { consecutive days }\end{array}$ & Maximum of the 3-day cumulative rainfall sequences over JJAS & $\mathrm{mm}$ \\
\hline CDD: maximum of consecutive dry days & Maximum of days with precipitation $<1 \mathrm{~mm}$ over JJAS & Days \\
\hline CDDT: mean time of the consecutive dry days & Medium date arising between the beginning and the end of the CDD & Julian day \\
\hline
\end{tabular}

purposes, the consequences of a delayed onset can be reduced by a later retreat. Also, from a climate change point of view, it is important to understand whether the length of the rainy season (retreat date minus onset date) will change significantly (e.g. Biasutti and Sobel 2009). Figure 9 displays the Julian date of the local retreat occurrence from observations, ERAI and RCMs driven by ERAI. ARC2 (Fig. 9a) reveals a progressive meridional retreat of the monsoon, first by the end of August from the northern latitudes $\left(\sim 18^{\circ} \mathrm{N}\right)$, then in mid to late September for the $16-14^{\circ} \mathrm{N}$ bands. Finally, after mid-October, no more significant rainfall appears north of $10^{\circ} \mathrm{N}$. There seems to be a later retreat near the coastal region, probably due to the local humidity supplied by the low-level westerlies, and the role played by the Guinea plateau in inducing upward motion and local convection. In fact, over the Fouta Djallon area (Guinea), the convective activity is found to increase in frequency and intensity due to the orographic forcing of water vapor in an area of convergence between monsoon and Harmattan fluxes, with heavy rain released over the southwest side of the Guinea plateau. In general, the retreat is better captured by RCMs than the onset. In fact, the abrupt northward shift of the monsoon at its onset time contrasts with the smooth retreat of the ITCZ. Hence, the rain belt retreat is a larger scale phenomenon that is less abrupt, with weaker meridional gradients than the onset, and so the retreat is less complex to represent by reanalysis and RCMs. Except CRCM5 (Fig. 9d), which tends to simulate a noticeably earlier retreat (10-20 days earlier north of $\sim 14^{\circ} \mathrm{N}$ ), all RCMs improve the simulated retreat with respect to ERAI, especially CCLM, RACMO22T and RCA4 (although the last does not represent the onset particularly well). As for the onset, using GCMs as driving conditions (Fig. 13) for various RCMs generally keeps differences in the same range as when they are driven by ERAI. 
Table 4 Mean values of daily precipitation indices (described in Table 3)

\begin{tabular}{|c|c|c|c|c|c|c|c|c|c|c|c|c|c|c|}
\hline$\overline{1989-2008}$ & \multicolumn{2}{|c|}{ RMean } & \multicolumn{2}{|c|}{$\mathrm{R} 1 \mathrm{~mm}$} & \multicolumn{2}{|l|}{ SDII } & \multicolumn{2}{|c|}{$\mathrm{CDD}$} & \multicolumn{2}{|c|}{ CDDT } & \multicolumn{2}{|l|}{$\mathrm{R} 3 \mathrm{~d}$} & \multicolumn{2}{|c|}{$\mathrm{R} 20 \mathrm{~mm}$} \\
\hline CANRCM4_ERAI & $\begin{array}{l}4.1 \\
0.8\end{array}$ & $\begin{array}{l}5.4 \\
0.9\end{array}$ & $\begin{array}{l}54.2 \\
5.6\end{array}$ & $\begin{array}{l}87.8 \\
3.2\end{array}$ & $\begin{array}{l}7.6 \\
1.7\end{array}$ & $\begin{array}{l}6.1 \\
1.0\end{array}$ & $\begin{array}{l}22 \\
6\end{array}$ & $\begin{array}{l}3 \\
1\end{array}$ & $\begin{array}{l}179 \\
18\end{array}$ & $\begin{array}{l}206 \\
36\end{array}$ & $\begin{array}{l}88.1 \\
44.2\end{array}$ & $\begin{array}{l}89.8 \\
67.5\end{array}$ & $\begin{array}{l}3.4 \\
1.3\end{array}$ & $\begin{array}{l}1.2 \\
1.0\end{array}$ \\
\hline CRCM5_ERAI & $\begin{array}{l}4.0 \\
0.8\end{array}$ & $\begin{array}{l}1.6 \\
0.4\end{array}$ & $\begin{array}{l}32.6 \\
4.1\end{array}$ & $\begin{array}{l}26.9 \\
4.1\end{array}$ & $\begin{array}{l}11.6 \\
2.2\end{array}$ & $\begin{array}{l}5.2 \\
1.1\end{array}$ & $\begin{array}{l}28 \\
9\end{array}$ & $\begin{array}{l}22 \\
7\end{array}$ & $\begin{array}{l}182 \\
23\end{array}$ & $\begin{array}{l}214 \\
39\end{array}$ & $\begin{array}{l}67.9 \\
22.0\end{array}$ & $\begin{array}{l}28.2 \\
12.5\end{array}$ & $\begin{array}{l}5.2 \\
1.9\end{array}$ & $\begin{array}{l}0.6 \\
0.6\end{array}$ \\
\hline HIRHAM5_ERAI & $\begin{array}{l}4.2 \\
1.2\end{array}$ & $\begin{array}{l}5.7 \\
1.7\end{array}$ & $\begin{array}{l}30.8 \\
4.7\end{array}$ & $\begin{array}{l}42.6 \\
5.3\end{array}$ & $\begin{array}{l}13.0 \\
3.7\end{array}$ & $\begin{array}{l}12.7 \\
3.8\end{array}$ & $\begin{array}{l}29 \\
10\end{array}$ & $\begin{array}{l}10 \\
3\end{array}$ & $\begin{array}{l}176 \\
14\end{array}$ & $\begin{array}{l}188 \\
29\end{array}$ & $\begin{array}{l}114.0 \\
60.0\end{array}$ & $\begin{array}{l}180.6 \\
113.0\end{array}$ & $\begin{array}{l}5.6 \\
2.1\end{array}$ & $\begin{array}{l}5.9 \\
1.8\end{array}$ \\
\hline RCA4_ERAI & $\begin{array}{l}5.5 \\
0.9\end{array}$ & $\begin{array}{l}3.3 \\
0.4\end{array}$ & $\begin{array}{l}54.8 \\
5.6\end{array}$ & $\begin{array}{l}56.0 \\
4.3\end{array}$ & $\begin{array}{l}10.4 \\
2.4\end{array}$ & $\begin{array}{l}5.6 \\
0.5\end{array}$ & $\begin{array}{l}22 \\
7\end{array}$ & $\begin{array}{l}9 \\
3\end{array}$ & $\begin{array}{l}180 \\
21\end{array}$ & $\begin{array}{l}228 \\
44\end{array}$ & $\begin{array}{l}82.2 \\
41.4\end{array}$ & $\begin{array}{l}34.6 \\
9.5\end{array}$ & $\begin{array}{l}4.6 \\
2.0\end{array}$ & $\begin{array}{l}0.5 \\
0.5\end{array}$ \\
\hline CCLM_ERAI & $\begin{array}{l}2.6 \\
0.9\end{array}$ & $\begin{array}{l}4.6 \\
1.4\end{array}$ & $\begin{array}{l}24.8 \\
5.6\end{array}$ & $\begin{array}{l}35.7 \\
6.7\end{array}$ & $\begin{array}{l}9.2 \\
2.9\end{array}$ & $\begin{array}{l}13.1 \\
3.8\end{array}$ & $\begin{array}{l}38 \\
11\end{array}$ & $\begin{array}{l}15 \\
5\end{array}$ & $\begin{array}{l}176 \\
12\end{array}$ & $\begin{array}{l}185 \\
33\end{array}$ & $\begin{array}{l}67.4 \\
39.5\end{array}$ & $\begin{array}{l}127.7 \\
57.3\end{array}$ & $\begin{array}{l}3.3 \\
1.6\end{array}$ & $\begin{array}{l}5.2 \\
2.0\end{array}$ \\
\hline RACMO22T_ERAI & $\begin{array}{l}4.2 \\
1.1\end{array}$ & $\begin{array}{l}6.3 \\
1.9\end{array}$ & $\begin{array}{l}44.3 \\
5.6\end{array}$ & $\begin{array}{l}46.0 \\
5.6\end{array}$ & $\begin{array}{l}8.4 \\
2.5\end{array}$ & $\begin{array}{l}13.2 \\
4.2\end{array}$ & $\begin{array}{l}20 \\
8\end{array}$ & $\begin{array}{l}11 \\
4\end{array}$ & $\begin{array}{l}174 \\
17\end{array}$ & $\begin{array}{l}199 \\
39\end{array}$ & $\begin{array}{l}104.3 \\
52.8\end{array}$ & $\begin{array}{l}169.6 \\
71.7\end{array}$ & $\begin{array}{l}3.5 \\
1.7\end{array}$ & $\begin{array}{l}6.4 \\
2.4\end{array}$ \\
\hline ERAI & $\begin{array}{l}2.5 \\
0.6\end{array}$ & $\begin{array}{l}1.5 \\
0.4\end{array}$ & $\begin{array}{l}38.9 \\
5.5\end{array}$ & $\begin{array}{l}33.9 \\
7.8\end{array}$ & $\begin{array}{l}5.8 \\
1.0\end{array}$ & $\begin{array}{l}3.6 \\
0.8\end{array}$ & $\begin{array}{l}29 \\
8\end{array}$ & $\begin{array}{l}22 \\
8\end{array}$ & 171 & 179 & $\begin{array}{l}40.8 \\
20.0\end{array}$ & $\begin{array}{l}27.6 \\
18.6\end{array}$ & $\begin{array}{l}0.8 \\
0.7\end{array}$ & $\begin{array}{l}0.2 \\
0.3\end{array}$ \\
\hline $\mathrm{ARC} 2$ & $\begin{array}{l}3.9 \\
1.0\end{array}$ & $\begin{array}{l}3.5 \\
0.5\end{array}$ & $\begin{array}{l}33.0 \\
4.6\end{array}$ & $\begin{array}{l}33.3 \\
3.6\end{array}$ & $\begin{array}{l}12.1 \\
1.9\end{array}$ & $\begin{array}{l}10.3 \\
1.3\end{array}$ & $\begin{array}{l}20 \\
6\end{array}$ & $\begin{array}{l}12 \\
4\end{array}$ & $\begin{array}{l}180 \\
17\end{array}$ & $\begin{array}{l}210 \\
34\end{array}$ & $\begin{array}{l}63.6 \\
17.4\end{array}$ & $\begin{array}{l}53.6 \\
15.0\end{array}$ & $\begin{array}{l}5.3 \\
2.1\end{array}$ & $\begin{array}{l}3.9 \\
1.4\end{array}$ \\
\hline \multicolumn{15}{|l|}{ 1983-2005 } \\
\hline CANRCM4_CanESM2 & $\begin{array}{l}2.2 \\
0.5\end{array}$ & $\begin{array}{l}4.2 \\
0.7\end{array}$ & $\begin{array}{l}44.5 \\
5.4\end{array}$ & $\begin{array}{l}77.7 \\
5.3\end{array}$ & $\begin{array}{l}5.1 \\
1.1\end{array}$ & $\begin{array}{l}5.3 \\
1.1\end{array}$ & $\begin{array}{l}26 \\
8\end{array}$ & $\begin{array}{l}5 \\
2\end{array}$ & $\begin{array}{l}189 \\
25\end{array}$ & $\begin{array}{l}226 \\
36\end{array}$ & $\begin{array}{l}44.6 \\
30.1\end{array}$ & $\begin{array}{l}84.3 \\
67.6\end{array}$ & $\begin{array}{l}0.7 \\
0.7\end{array}$ & $\begin{array}{l}1.0 \\
1.0\end{array}$ \\
\hline CRCM5_CanESM2 & $\begin{array}{l}2.4 \\
0.7\end{array}$ & $\begin{array}{l}1.2 \\
0.3\end{array}$ & $\begin{array}{l}24.0 \\
4.3\end{array}$ & $\begin{array}{l}21.3 \\
4.0\end{array}$ & $\begin{array}{l}9.4 \\
2.2\end{array}$ & $\begin{array}{l}5.0 \\
1.2\end{array}$ & $\begin{array}{l}38 \\
12\end{array}$ & $\begin{array}{l}30 \\
9\end{array}$ & $\begin{array}{l}189 \\
26\end{array}$ & $\begin{array}{l}222 \\
36\end{array}$ & $\begin{array}{l}49.2 \\
20.2\end{array}$ & $\begin{array}{l}25.1 \\
11.7\end{array}$ & $\begin{array}{l}2.7 \\
1.5\end{array}$ & $\begin{array}{l}0.4 \\
0.5\end{array}$ \\
\hline CRCM5_MPI & $\begin{array}{l}4.4 \\
1.1\end{array}$ & $\begin{array}{l}1.5 \\
0.4\end{array}$ & $\begin{array}{l}34.0 \\
5.0\end{array}$ & $\begin{array}{l}25.6 \\
4.9\end{array}$ & $\begin{array}{l}12.3 \\
2.8\end{array}$ & $\begin{array}{l}5.1 \\
1.2\end{array}$ & $\begin{array}{l}21 \\
8\end{array}$ & $\begin{array}{l}24 \\
10\end{array}$ & $\begin{array}{l}177 \\
24\end{array}$ & $\begin{array}{l}195 \\
31\end{array}$ & $\begin{array}{l}82.6 \\
30.5\end{array}$ & $\begin{array}{l}29.6 \\
16.6\end{array}$ & $\begin{array}{l}6.0 \\
2.3\end{array}$ & $\begin{array}{l}0.5 \\
0.6\end{array}$ \\
\hline HIRHAM5_EC-EARTH & $\begin{array}{l}3.9 \\
1.1\end{array}$ & $\begin{array}{l}4.8 \\
1.4\end{array}$ & $\begin{array}{l}35.3 \\
6.8\end{array}$ & $\begin{array}{l}44.9 \\
5.9\end{array}$ & $\begin{array}{l}10.6 \\
2.7\end{array}$ & $\begin{array}{l}10.5 \\
3.0\end{array}$ & $\begin{array}{l}21 \\
8\end{array}$ & $\begin{array}{l}10 \\
4\end{array}$ & $\begin{array}{l}193 \\
28\end{array}$ & $\begin{array}{l}196 \\
37\end{array}$ & $\begin{array}{l}94.0 \\
51.4\end{array}$ & $\begin{array}{l}127.9 \\
84.1\end{array}$ & $\begin{array}{l}4.5 \\
1.9\end{array}$ & $\begin{array}{l}5.1 \\
2.2\end{array}$ \\
\hline RCA4_CanESM2 & $\begin{array}{l}2.9 \\
0.6\end{array}$ & $\begin{array}{l}2.1 \\
0.4\end{array}$ & $\begin{array}{l}36.9 \\
5.0\end{array}$ & $\begin{array}{l}40.1 \\
5.8\end{array}$ & $\begin{array}{l}7.4 \\
1.4\end{array}$ & $\begin{array}{l}4.9 \\
0.6\end{array}$ & $\begin{array}{l}36 \\
11\end{array}$ & $\begin{array}{l}19 \\
7\end{array}$ & $\begin{array}{l}188 \\
25\end{array}$ & $\begin{array}{l}238 \\
40\end{array}$ & $\begin{array}{l}41.2 \\
16.9\end{array}$ & $\begin{array}{l}27.7 \\
8.4\end{array}$ & $\begin{array}{l}1.6 \\
1.1\end{array}$ & $\begin{array}{l}0.2 \\
0.4\end{array}$ \\
\hline RCA4_EC-EARTH & $\begin{array}{l}4.2 \\
1.0\end{array}$ & $\begin{array}{l}2.7 \\
0.4\end{array}$ & $\begin{array}{l}45.5 \\
6.3\end{array}$ & $\begin{array}{l}48.8 \\
4.5\end{array}$ & $\begin{array}{l}9.3 \\
3.2\end{array}$ & $\begin{array}{l}5.2 \\
0.7\end{array}$ & $\begin{array}{l}23 \\
8\end{array}$ & $\begin{array}{l}12 \\
4\end{array}$ & $\begin{array}{l}188 \\
31\end{array}$ & $\begin{array}{l}234 \\
41\end{array}$ & $\begin{array}{l}68.4 \\
40.1\end{array}$ & $\begin{array}{l}36.2 \\
16.7\end{array}$ & $\begin{array}{l}3.0 \\
1.9\end{array}$ & $\begin{array}{l}0.5 \\
0.7\end{array}$ \\
\hline RCA4_MPI & $\begin{array}{l}5.0 \\
1.0\end{array}$ & $\begin{array}{l}2.9 \\
0.6\end{array}$ & $\begin{array}{l}47.2 \\
5.3\end{array}$ & $\begin{array}{l}47.5 \\
5.8\end{array}$ & $\begin{array}{l}12.0 \\
4.5\end{array}$ & $\begin{array}{l}5.7 \\
1.0\end{array}$ & $\begin{array}{l}22 \\
7\end{array}$ & $\begin{array}{l}12 \\
5\end{array}$ & $\begin{array}{l}181 \\
24\end{array}$ & $\begin{array}{l}204 \\
41\end{array}$ & $\begin{array}{l}96.8 \\
54.6\end{array}$ & $\begin{array}{l}45.1 \\
25.9\end{array}$ & $\begin{array}{l}4.7 \\
1.9\end{array}$ & $\begin{array}{l}1.0 \\
1.0\end{array}$ \\
\hline CCLM_EC-EARTH & $\begin{array}{l}2.2 \\
0.9\end{array}$ & $\begin{array}{l}5.5 \\
1.6\end{array}$ & $\begin{array}{l}23.5 \\
6.5\end{array}$ & $\begin{array}{l}48.6 \\
6.9\end{array}$ & $\begin{array}{l}9.0 \\
3.2\end{array}$ & $\begin{array}{l}11.5 \\
3.2\end{array}$ & $\begin{array}{l}30 \\
11\end{array}$ & $\begin{array}{l}11 \\
4\end{array}$ & $\begin{array}{l}192 \\
30\end{array}$ & $\begin{array}{l}190 \\
37\end{array}$ & $\begin{array}{l}72.2 \\
48.9\end{array}$ & $\begin{array}{l}143.3 \\
65.5\end{array}$ & $\begin{array}{l}2.4 \\
1.5\end{array}$ & $\begin{array}{l}5.4 \\
2.2\end{array}$ \\
\hline CCLM_MPI & $\begin{array}{l}3.1 \\
1.4\end{array}$ & $\begin{array}{l}5.0 \\
1.6\end{array}$ & $\begin{array}{l}27.1 \\
7.1\end{array}$ & $\begin{array}{l}38.2 \\
6.8\end{array}$ & $\begin{array}{l}10.8 \\
4.1\end{array}$ & $\begin{array}{l}13.4 \\
3.9\end{array}$ & $\begin{array}{l}28 \\
10\end{array}$ & $\begin{array}{l}14 \\
5\end{array}$ & $\begin{array}{l}178 \\
20\end{array}$ & $\begin{array}{l}186 \\
31\end{array}$ & $\begin{array}{l}97.5 \\
69.6\end{array}$ & $\begin{array}{l}145.3 \\
68.9\end{array}$ & $\begin{array}{l}3.7 \\
2.0\end{array}$ & $\begin{array}{l}5.4 \\
2.1\end{array}$ \\
\hline RACMO22T_EC-EARTH & $\begin{array}{l}3.7 \\
1.2\end{array}$ & $\begin{array}{l}5.1 \\
1.6\end{array}$ & $\begin{array}{l}47.0 \\
6.9\end{array}$ & $\begin{array}{l}48.4 \\
7.5\end{array}$ & $\begin{array}{l}7.3 \\
2.3\end{array}$ & $\begin{array}{l}10.0 \\
3.1\end{array}$ & $\begin{array}{l}14 \\
6\end{array}$ & $\begin{array}{l}13 \\
5\end{array}$ & $\begin{array}{l}201 \\
40\end{array}$ & $\begin{array}{l}194 \\
36\end{array}$ & $\begin{array}{l}92.2 \\
49.3\end{array}$ & $\begin{array}{l}137.5 \\
69.6\end{array}$ & $\begin{array}{l}2.7 \\
1.7\end{array}$ & $\begin{array}{l}4.9 \\
2.2\end{array}$ \\
\hline ERAI & $\begin{array}{l}2.5 \\
0.6\end{array}$ & $\begin{array}{l}1.6 \\
0.5\end{array}$ & $\begin{array}{l}38.3 \\
5.4\end{array}$ & $\begin{array}{l}36.2 \\
7.6\end{array}$ & $\begin{array}{l}5.8 \\
1.0\end{array}$ & $\begin{array}{l}3.6 \\
0.8\end{array}$ & $\begin{array}{l}30 \\
9\end{array}$ & $\begin{array}{l}19 \\
7\end{array}$ & 172 & 179 & $\begin{array}{l}40.4 \\
18.9\end{array}$ & $\begin{array}{l}27.9 \\
19.0\end{array}$ & $\begin{array}{l}0.8 \\
0.7\end{array}$ & $\begin{array}{l}0.2 \\
0.3\end{array}$ \\
\hline $\mathrm{ARC} 2$ & $\begin{array}{l}3.4 \\
0.9\end{array}$ & $\begin{array}{l}2.8 \\
0.8\end{array}$ & $\begin{array}{l}30.3 \\
4.6\end{array}$ & $\begin{array}{l}31.5 \\
4.6\end{array}$ & $\begin{array}{l}11.5 \\
1.8\end{array}$ & $\begin{array}{l}8.8 \\
1.8\end{array}$ & $\begin{array}{l}19 \\
7\end{array}$ & $\begin{array}{l}12 \\
3\end{array}$ & $\begin{array}{l}180 \\
19\end{array}$ & $\begin{array}{l}205 \\
34\end{array}$ & $\begin{array}{l}63.5 \\
20.9\end{array}$ & $\begin{array}{l}54.5 \\
19.4\end{array}$ & $\begin{array}{l}4.7 \\
1.8\end{array}$ & $\begin{array}{l}2.9 \\
1.5\end{array}$ \\
\hline \multicolumn{15}{|l|}{ 1998-2009 } \\
\hline GPCP & $\begin{array}{l}4.7 \\
0.7\end{array}$ & $\begin{array}{l}3.8 \\
0.6\end{array}$ & $\begin{array}{l}39.5 \\
5.0\end{array}$ & $\begin{array}{l}30.86 \\
3.92\end{array}$ & $\begin{array}{l}11.4 \\
1.4\end{array}$ & $\begin{array}{l}11.7 \\
1.3\end{array}$ & $\begin{array}{l}16 \\
5\end{array}$ & $\begin{array}{l}13 \\
3\end{array}$ & $\begin{array}{l}175 \\
15\end{array}$ & $\begin{array}{l}198 \\
32\end{array}$ & $\begin{array}{l}65.5 \\
13.1\end{array}$ & $\begin{array}{l}57.9 \\
12.6\end{array}$ & $\begin{array}{l}7.3 \\
2.0\end{array}$ & $\begin{array}{l}6.3 \\
1.5\end{array}$ \\
\hline TRMM & $\begin{array}{l}4.1 \\
1.0\end{array}$ & $\begin{array}{l}3.7 \\
0.7\end{array}$ & $\begin{array}{l}28.2 \\
5.0\end{array}$ & $\begin{array}{l}23.89 \\
4.52\end{array}$ & $\begin{array}{l}14.5 \\
3.3\end{array}$ & $\begin{array}{l}16.0 \\
4.2\end{array}$ & $\begin{array}{l}22 \\
7\end{array}$ & $\begin{array}{l}16 \\
6\end{array}$ & $\begin{array}{l}178 \\
17\end{array}$ & $\begin{array}{l}202 \\
34\end{array}$ & $\begin{array}{l}88.7 \\
29.2\end{array}$ & $\begin{array}{l}80.2 \\
26.3\end{array}$ & $\begin{array}{l}6.3 \\
2.0\end{array}$ & $\begin{array}{l}5.7 \\
1.6\end{array}$ \\
\hline $\mathrm{ARC} 2$ & $\begin{array}{l}3.9 \\
1.0\end{array}$ & $\begin{array}{l}3.5 \\
0.5\end{array}$ & $\begin{array}{l}33.0 \\
4.6\end{array}$ & $\begin{array}{l}33.3 \\
3.6\end{array}$ & $\begin{array}{l}12.1 \\
1.9\end{array}$ & $\begin{array}{l}10.3 \\
1.3\end{array}$ & $\begin{array}{l}20 \\
6\end{array}$ & $\begin{array}{l}12 \\
4\end{array}$ & $\begin{array}{l}177 \\
15\end{array}$ & $\begin{array}{l}209 \\
35\end{array}$ & $\begin{array}{l}63.6 \\
17.4\end{array}$ & $\begin{array}{l}53.6 \\
15.0\end{array}$ & $\begin{array}{l}5.3 \\
2.1\end{array}$ & $\begin{array}{l}3.9 \\
1.4\end{array}$ \\
\hline
\end{tabular}

For each index, the left (right) values are computed over the coastal (continental) regions. The first (top) value is the JJAS average over different periods: 1989-2008 for ARC2 and ERAI-driven RCMs; 1983-2005 for ACR2 and GCM-driven RCMs and 1998-2008 for ARC2, TRMM and GPCP. The second (bottom value is the index temporal standard deviation. The reference ARC2 is highlighted in bold 


\subsection{Daily precipitation indices: definitions}

The daily precipitation indices are assessed with respect to three criteria: the occurrence, the intensity and the duration of a given rainy event. Gachon et al. (2007) performed a quantitative analysis of a larger number of indices over the Sahel region using ground-based observations. The indices used in the current analysis are presented in Table 3 using the same definition as in Gachon et al. (2007) and Diaconescu et al. (2015).

$\mathrm{R} 1 \mathrm{~mm}$ is related to the occurrence of rainy events (defined as daily precipitation $\geq 1 \mathrm{~mm} \mathrm{day}^{-1}$ ), while other indices such as SDII, R20mm or Rd3 account for both occurrence and intensity (i.e. mean intensity per wet day, percentage of days with daily precipitation $\geq 20 \mathrm{~mm} / \mathrm{day}$, or maximum amount of rainfall over three consecutive days, respectively). CDD is the dry spell index (maximum number of Consecutive Dry Days). According to Gachon et al. (2007), $20 \mathrm{~mm} \mathrm{day}^{-1}$ falls climatologically within the $70^{\text {th }}$ and the $80^{\text {th }}$ percentiles of daily rainfall over the Sahel. In a Sahelian context with strong vulnerability as well as large needs concerning water supply, the moderate to heavy rainy events require due consideration. With the $\mathrm{Rd} 3$ and $\mathrm{R} 20 \mathrm{~mm}$ indices, the ability of RCMs to capture these relatively important events is then evaluated. The CDD index is also of great interest for farming activities. Overall, in a future climate-change perspective, it can be interesting in terms of agricultural adaptation (e.g. choice of crop variety).

\subsection{Daily precipitation indices: performance matrix}

A performance matrix is used to summarize the results of the evaluation of the daily precipitation indices (defined in Table 3). Gleckler et al. (2008) have discussed the interest of using objective metrics to compare simulations and also the systematic related difficulties, which include the availability and the quality of reference observational data, and the lack of accepted standard measures of model performance. The metric used in the study of Gleckler et al. (2008) was the relative RMSE against the "typical" error for all models, which is the median RMSE for a given index. In the present study, given the relatively limited number of RCMs, this "typical" error is not used and, instead, the maximum RMSE is used so that the "best" possible performer (which is the reference itself) will have 0 while the "less" skillful RCMs will have a score of 1 . In this manner, the performance matrix has the advantage of ranking models (relatively to a particular criterion) without losing the information on their individual deviation with respect to the reference. Table 4 shows the actual values of mean and standard deviation for each index over the periods where data are available.
Figure 10 presents the performance matrix for the 6 ERAI-driven RCMs, ERAI, TRMM and GPCP (the last 2 are used for 1998-2008) with respect to ARC2, for the continental (bottom triangle) and the coastal (upper triangle) sub-regions. In general, there is a large spread between datasets and among indices within the same dataset. First, TRMM and GPCP analyses of observations show a reasonable consistency with ARC2 for all indices except the SDII and R20mm (i.e. for moderate- and high-intensity rainfall), consistently with Sylla et al. (2012) who showed marked discrepancies among observations for higher-order indices. For most of the indices, observations clearly differ from models by their smaller RMSE (for mean rainfall, number of wet days, the maximum rainfall cumulated over three consecutive days and finally the longest dry spell). In addition, Table 4 shows an appreciable consistency between GPCP and ARC2 over the continental region: on average 31 wet days for GPCP against 33 for ARC2; 13 CDD with day 198 (around mid-July) as the medium date of occurrence for GPCP against 12 CDD occurring around day 208 for ARC2; and, finally, 58 mm as R3d for GPCP against $\sim 54 \mathrm{~mm}$ for ARC2. TRMM indices show larger discrepancies that cannot be explained solely by the difference of resolution since GPCP is even coarser.

For the Simple Daily Intensity Index (SDII) and R20mm index, substantial differences exist between observations. A large discrepancy arises between ARC2 and TRMM in terms of SDII over the continent, TRMM giving $16 \mathrm{~mm} \mathrm{day}^{-1}$ while ARC2 notes only $10 \mathrm{~mm} \mathrm{day}^{-1}$. This is probably due to the fact that TRMM tends to overestimate precipitation over the Sahel (e.g. Fig. 8a) and ARC2 to underestimate it (Novella and Thiaw 2012). Considering the R20mm, TRMM appears to be the closest to ARC2 for both regions and this implies that the differences between these two observations in SDII come from moderate to lower (than $20 \mathrm{~mm} \mathrm{day}^{-1}$ ) intensity rainfall.

ERAI shows quite good and equivalent behavior in both coastal and continental regions, except for the CDD index, which is the least well reproduced over the continental area, as also noted north of $17^{\circ} \mathrm{N}$ with a dry bias over this region (see Fig. 2b). Among all the models, the mean precipitation and the occurrence of wet days are best reproduced by ERAI over both regions. As a reanalysis, ERAI can be expected to capture the main features of the monsoon weather (like relatively large-scale phenomena such as AEWs) and therefore be "accurate" in finding their average effect. In fact, Diaconescu et al. (2015) showed that ERAI presented higher correlation (in comparison with the 2 Canadian RCMs) as well as smaller R1mm RMSE relatively to observations. However, for the moderate- to high-intensity rainfall indices (i.e., SDII and R20mm), ERAI performed poorly, with the lowest skill of all models over the coast. In fact, ERAI produced insufficient 


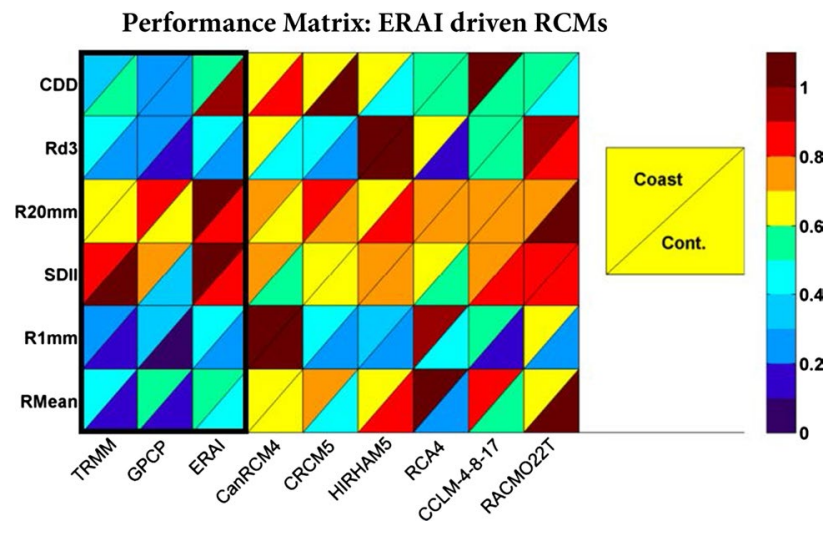

Fig. 10 Daily precipitation index performance matrix. For a given index, values are computed as the ratio between each dataset RMSE and the maximum value of all datasets RMSE. The RMSE is computed against ARC2 rainfall

rainfall values (i.e. fewer occurrences of intense rainfall), with SDIIs of $\sim 6$ and $12 \mathrm{~mm} \mathrm{day}^{-1}$ and R20mms of $\sim 1$ and $5 \mathrm{~mm}$ day $^{-1}$ for ERAI and ARC2, respectively (see Table 4).

The large majority of RCMs exhibit behavior that is similar to (but less good than) that of ERAI when RMean and $\mathrm{R} 1 \mathrm{~mm}$ are considered, but this varies between the two regions. For example, for RMean, RCA4 presents the highest/lowest relative RMSE over the coast/continent. CanRCM4 overestimates the wet days (R1mm) over the continent with $\sim 88$ wet days against 33 for ARC2, consistently with its too-early onset (Fig. 8c) over this area. Conversely, CRCM5 and HIRHAM5 are quite similar to ERAI, with quite accurate numbers of wet days. The SDII and R20mm are better reproduced by most of RCMs (except RAC$\mathrm{MO} 22 \mathrm{~T}$ ) than by ERAI. This is in line with our previous analysis showing that RCMs resolve the physics of moderate to heavy rainy events better, with a significant added value. For example, using the ensemble mean of $10 \mathrm{RCMs}$ (including the 6 used here), Klutse et al. (2015) evaluated the correlation with observations at more than 0.8 over the Sahel for extreme precipitation. Finally, for these two indices, RCM skill with respect to ARC2 is similar to those from various observed data and, in some cases, even better (RCA4 and CRCM5 for the SDII index).

The Rd3 and the CDD indices are used to characterize the strongest accumulation of rain during a 3-day wet spell, and the longest dry spell, respectively. In fact, their occurrence and persistence during the monsoon season are of high importance for the socio-economic activities of the Sahel. A large spread in terms of skills can be observed among RCMs regarding these two indices in Fig. 10. The overall weakness of RCM performances for these two indices recalls the analysis in Sect. 4: despite improving (relative to ERAI) the representation of high-frequency variability, RCMs still misrepresent the spectrum of these time scales directly influenced by the meteorological events and their high-frequency distribution. Furthermore, RCMs perform CDD and Rd3 with two apparently contradictory tendencies. For example, CRCM5 performs well for Rd3 over both coastal and continental regions but it exhibits one of the largest errors for CDD. On the other hand, the best CDD obtained with RACMO22T and HIRHAM5 contrasts with their smallest skill for Rd3. As noted by Crétat et al. (2013), these different behaviors in RCMs are potentially linked with their physical parameterizations, i.e. intermittency of convective precipitation, but deeper investigations (outside the scope of the present study) are needed to better study the question. Finally, when driven by GCMs (Fig. 14), RCM skill globally tends to decrease regardless of the region but their "ranking" does not change. Even surprisingly, the SDII and the R20mm indices remain slightly improved relatively to ERAI ones for most of the RCMs.

\section{Conclusion and future work}

During recent years, notable progress has been made in understanding WAM dynamics and the related physical processes (e.g. review by Nicholson 2013) as well as its socio-economic stakes (e.g. Moron et al. 2015). Awareness of ongoing climate-change impacts is also growing and, more than ever, adaptation, mitigation and resilience policies need to be developed for the Sahel area. In this context, improved weather/climate information, including simulations, are required and a considerable number of projects (including CORDEX-Africa) have been setup to meet this need. Our study is an attempt to provide a verification of these simulations by addressing one crucial aspect of the WAM field, its intraseasonal variability.

The study combines the daily rainfall and precipitable water to evaluate the RCM CORDEX simulations over the WAM region. Although relevant for the Sahelian weather analysis, $P W$ derived from RCMs has never been analyzed in climatological mode. The evaluation of six RCMs driven by ERAI and by three GCMs (in Appendix) is performed using ERAI and ARC2 verification data. The climatology of observed precipitation and reanalyzed $P W$ confirms previous findings: (1) the $30-\mathrm{mm} P W$ contour is approximately the threshold below which precipitation hardly occurs, (2) the Sahel $\left(12-20^{\circ} \mathrm{N}\right)$ is characterized by a sharp $P W$ gradient consistent with a sharp decrease in precipitation northward, (3) even though ERAI has a relatively accurate $P W$, it fails to capture the summer rain belt position.

Furthermore, RCMs have been evaluated through their simulated seasonal precipitation and $P W$. This reveals three different tendencies in model behaviors over the Sahel baroclinic zone: (1) models that exhibit a northward bias 
in the position of the monsoon (e.g. CCLM, RACMO22T, CanRCM4 and, to some extent, HIRHAM5) are too moist over the Sahel and therefore displace the baroclinic zone towards the Sahara; this group of RCMs shows a systematic overly wet monsoon between 10 and $15^{\circ} \mathrm{N}$ and abnormally humid Sahel between 15 and $20^{\circ} \mathrm{N}$; (2) models that exhibit a southward bias in the position of the monsoon (e.g. CRCM5), despite capturing the structure of the baroclinic zone associated $P W$ gradients, keep the rainy belt trapped in southern West Africa (around $10^{\circ} \mathrm{N}$ ) as does ERAI, leading to a relatively dry Sahel; and, finally (3) some models, such as RCA4 that have the merit of representing seasonal structures that are close enough to both ERAI $P W$ and $\mathrm{ARC} 2$ rainfall.

Considering the intraseasonal scales, models have been assessed regarding their variance distribution in two intraseasonal subscales, the low-frequency scale (longer than 10-day period) and the high-frequency scale (shorter than 10-day period), which are mainly attributable to synoptic and meteorological events. In terms of $P W$ variability, RCMs tend to overestimate the intraseasonal anomalies over the continental Sahel. More specifically, time scales longer than 10 days make an excessively strong contribution, instead of synoptic scales as shown by ERAI. Over the western coast, most RCMs are able to reproduce highfrequency features mainly due to the westward growing AEW systems. Finally, it appears that, regardless of the region, RCMs skills in reproducing the intraseasonal subscales decrease when they are driven by GCMs instead of ERAI.

Furthermore, the study investigates the frequency-time distribution of rainfall predicted by RCMs through spectrum analysis. The 2009 summer season, characterized by intense rainfall in September and an associated flooding event, is examined in the light of ARC2 wavelet analysis and illustrates two aspects: (1) the poor representation of ERAI regarding the shorter scale events, leading to a relatively flat precipitation time series, and (2) in RCMs, the relative excess of high-frequency activity, despite lowfrequency activity being overestimated. The analysis of the whole period (1989-2008) allows the 2009 summer case results to be generalized to RCMs, which tend to improve the representation of synoptic scales within the whole intraseasonal spectrum by increasing the presence of very short time scales ( $<3$ days). Such scales are influenced by the well-known MCSs (or SLs), usually embedded in AEWs or sometimes generated more locally when surface conditions are favorable. The interactions between MCSs and AEWs are complicated by the fact that, while being closely related, they occur at different time and space scales. The analysis implies that RCMs partly resolve this critical issue even though some improvements are still needed.
The last part of the study focuses on the evaluation of daily precipitation indices related to the occurrence, intensity and persistence of rainfall, and on the monsoon onset/ retreat. The one-moment indices (JJAS mean rainfall, wet days) are relatively well calculated by ERAI, and RCM simulations are more or less similar to ERAI depending on whether the continental or the coastal region is considered. When higher-order indices are used (SDII or R20 mm), the skills of both observations and simulations decrease drastically, revealing the difficulty of representing the occurrence and duration of intense events. Nevertheless, the statistics from RCMs are relatively better, in general, than those from ERAI. This result is consistent with the scales analysis that highlights the inability of ERAI to capture individual meteorological events, namely the MCSs responsible for moderate to heavy rainfall.

A recent review by Di Luca et al. (2015) on the added value of RCMs pointed out a real difficulty in defining and deriving their added values. Regarding the Sahelian context, we believe that the present paper proposes an interesting way of assessing, at least qualitatively, the added value of RCMs relatively to coarser (or less resolved) model simulations. From our study and reviews of previous literature, the main successes (+) and challenges (-) of the RCM approach can be summarized as:

\section{The mean state:}

(+) The seasonal mean state of the WAM precipitation is improved (in comparison with reanalyses and GCMs) and systematic biases are reduced due to a better representation of monsoon fluxes and interactions with diverse land surfaces.

(-) There are still some important biases over the northern flank of the Sahel (north of $15^{\circ} \mathrm{N}$ ), the southern Guinea ocean-continent border and the topographic areas where smaller/local scale processes seem to play an important role.

2. The intraseasonal scales:

(+) The intraseasonal spectrum is better resolved through more important temporal and spatial variability of rainfall. The 1-10 day scale phenomena such as AEWs and the related convective activity have more realistic impact on the shape of the spectrum.

(-) Like ERAI, RCMs still overestimate the lowfrequency (10-90-day) activity and this has the effect of artificially increasing the intraseasonal variability in general. In addition, the well-known separation of the "short" intraseasonal scale (1025-day) and the "long" one (25-60-day) does not 
appear clearly. This implies, for instance, that RCMs would hardly capture the MJO effects over the WAM region.

\section{The WAM onset/retreat:}

(+) Two RCMs really improve the simulation of the local onset. Interestingly, it is found that a good representation of the energy balance between low-frequency/high-frequency, rather than a good seasonal mean structure, leads to a remarkably good onset structure. The monsoon retreat is handled pretty well by the majority of RCMs.

(-) Consistently, because of exaggeration of the impact of low-frequencies, some RCMs completely misrepresent the meridional structure of the onset, leading to unrealistic occurrence dates.

4. The daily precipitation indices:

(+) In comparison with ERAI (comparison with GCMs is still needed), RCMs tend to predict the occurrence and intensity of moderate to high precipitation events better. This appears to be related to the improvement of meteorological scale phenomena (e.g. MCSs).

(-) ERAI outperforms all RCMs in terms of wet day occurrence and seasonal mean precipitation correlation. This result was to be expected since RCMs could hardly capture the chronology of meteorological events.

In a context of climate change, a growing number of applications are expected to favor the development of adaptation strategies and mitigation policies. For the Sahel, many issues hinge on the quality of the monsoon prediction and thus of its intraseasonal activity over the current and future periods. This study lays the basis for understanding such aspects starting from RCM historical simulations. Future work will be directed toward answering two parallel questions: (1) How (and why) do RCMs represent the intraseasonal variability of the WAM according to the different climate scenarios? (2) Which aspects of RCM physics and/ or dynamics can be improved to reduce the impact of lowfrequency timescale biases on the intraseasonality of the monsoon? In line with some recent works (e.g. Diallo et al. 2012, Vizy et al. 2013), these aspects will be considered in further studies by means of an ensemble of RCM runs using various combinations of RCM/GCM downscaling over the WAM area. As implied in this study, those further works will need substantial analysis of physical processes at meteorological scales, as it is crucial to resolve this scale well for any climatological application.

Acknowledgments The authors acknowledge the financial support of the International Research Initiative on Adaptation to Climate Change (IRIACC)-Faire face aux Changements Ensemble (FACE) project (http://face.ete.inrs.ca/). IRIACC is co-financed and managed by the International Development Research Centre (IDRC), the Canadian Institutes of Health Research (CIHR), the Social Sciences and Humanities Research Council of Canada (SSHRC) and the Natural Sciences and Engineering Research Council of Canada (NSERC). We are also grateful to the Centre pour l'Étude et la Simulation du Climat à l'Échelle Régionale (ESCER) of the Université du Québec à Montréal (UQAM) and to the various CORDEX modeling groups, who provided the outputs of all RCM simulations used in our study. We would like to thank the $\mathrm{CCCma/EC}$ who provided information and output files for CanRCM4, and Ms. Katja Winger and Prof. Laxmi Sushama at UQAM who provided information and output files from CRCM5. We also acknowledge the developers of the ARC2, GPCP, TRMM and ERA-Interim data sets. The ARC2 dataset was downloaded from their ftp site (ftp://ftp.cpc.ncep.noaa.gov/fews/fewsdata/ africa/arc2/), while the TRMM and GPCP data are available at NASA Goddard Space Flight Center's site (http://precip.gsfc.nasa.gov/). Finally, the authors are sincerely grateful to the three anonymous reviewers as well as Susan Becker who helped to improve the paper in terms of clarity and scientific messages as well as contextualizing these results.

Open Access This article is distributed under the terms of the Creative Commons Attribution 4.0 International License (http://creativecommons.org/licenses/by/4.0/), which permits unrestricted use, distribution, and reproduction in any medium, provided you give appropriate credit to the original author(s) and the source, provide a link to the Creative Commons license, and indicate if changes were made.

\section{Appendix}

See Figs. 11, 12, 13 and 14. 
Fig. 11 Normalized PSD (in \%) for ERAI (red) and ARC2 (blue) over the coastal (left) and the continental (right) regions. The shaded area represents the range of values of the 6 RCM PSDs

(a) ARC2

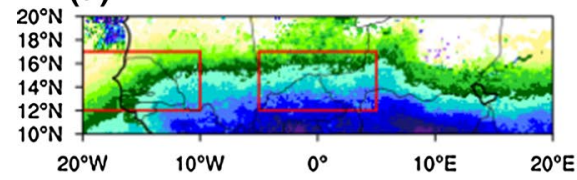

(d) HIRHAM5_EC-EARTH

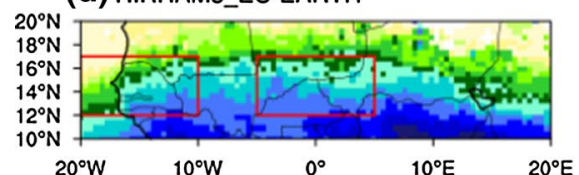

(b) ERAI

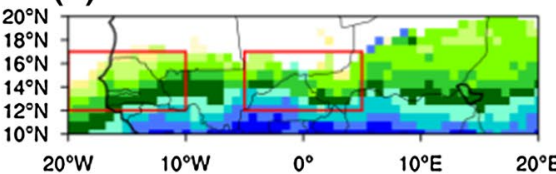

(e) CRCM5_MPI

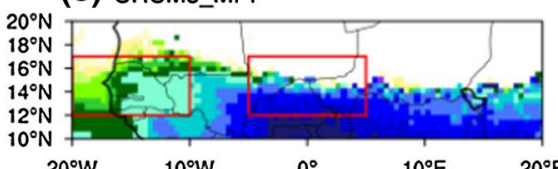

(h) RCA4_MPI
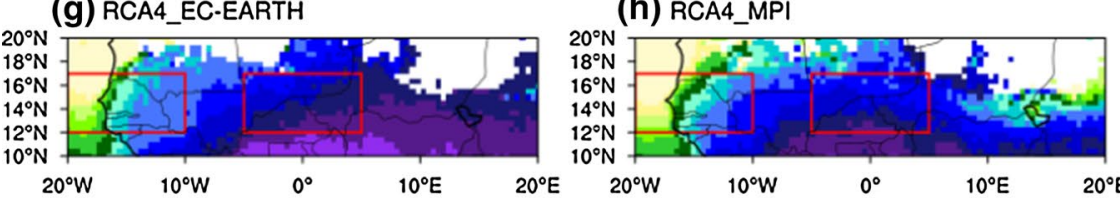

(j) CCLM-4-8-17_EC-EARTH

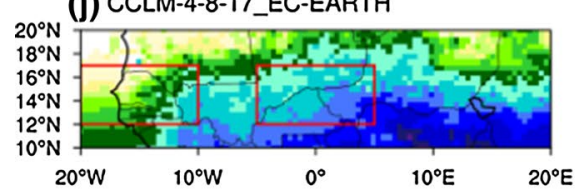

(k) CCLM-4-8-17_MPI

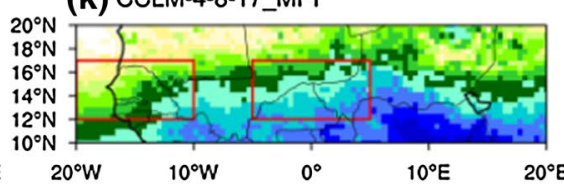

(c) CanRCM4_CanESM2
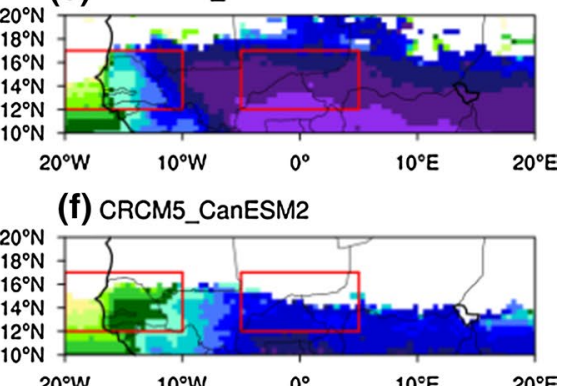

(i) RCA4_CanESM2

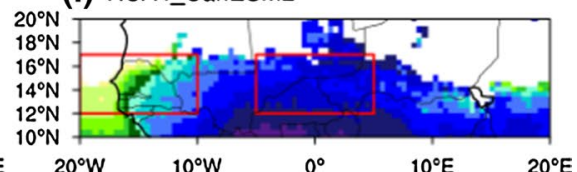

(I)RACMO22T_EC-EARTH

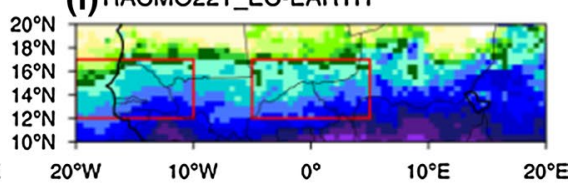

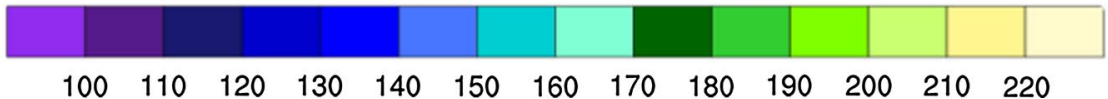

Fig. 12 Same as Fig. 8, but for GCM-driven RCMs (the titles give the names of both the RCM and the driving GCM): Local monsoon onset dates in day of year 
(a) ARC2

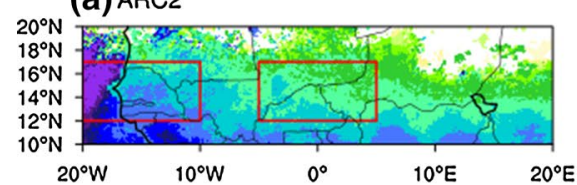

(d) HIRHAM5_EC-EARTH

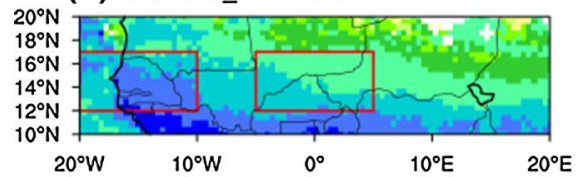

(g) RCA4_EC-EARTH

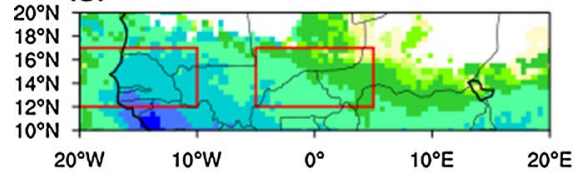

(j) CCLM-4-8-17_EC-EARTH

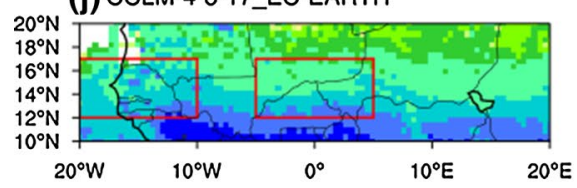

(b) ERAI

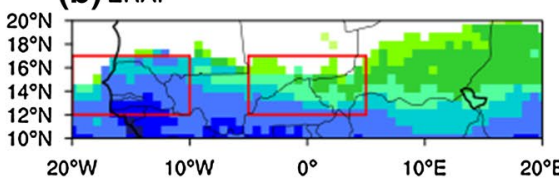

(e) CRCM5_MPI

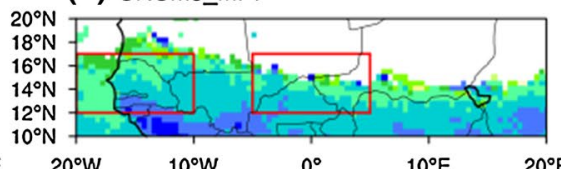

(h) RCA4_MPI

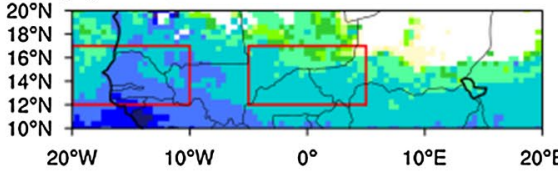

(k) CCLM-4-8-17_MPI

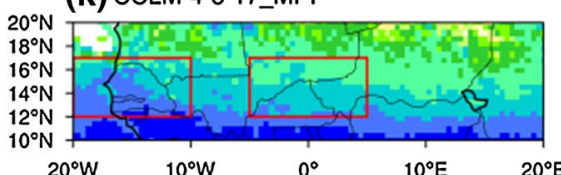

(c) CanRCM4_CanESM2

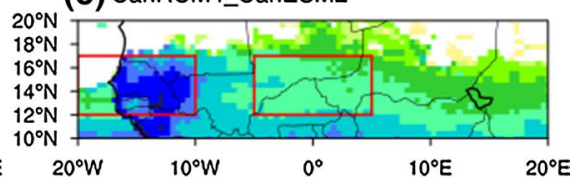

(f) CRCM5_CanESM2

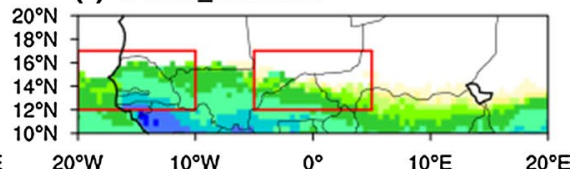

(i) RCA4_CanESM2

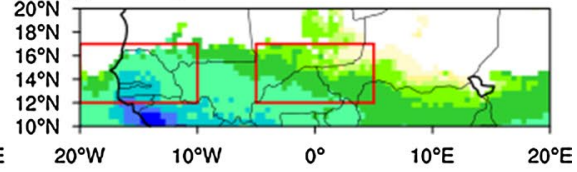

(I) RACMO22T_EC-EARTH

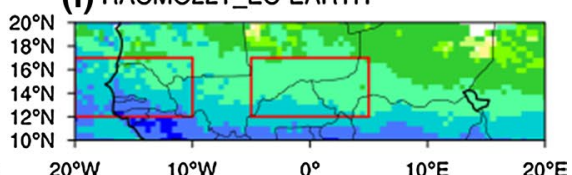

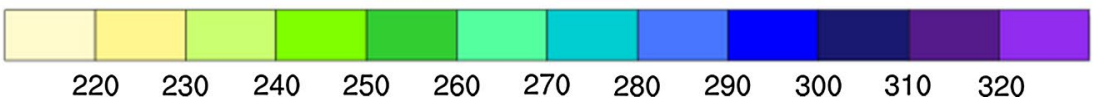

Fig. 13 Same as Fig. 9, but for GCM-driven RCMs (the titles quote both RCM and driving GCM names): local monsoon retreat occurrence dates in day of year

Fig. 14 Same as Fig. 10 but for GCM-driven RCMs: daily precipitation index performance matrix. For a given index, values are computed as the ratio between each dataset RMSE and the maximum value of all datasets. The RMSE is computed against $\mathrm{ARC} 2$ rainfall

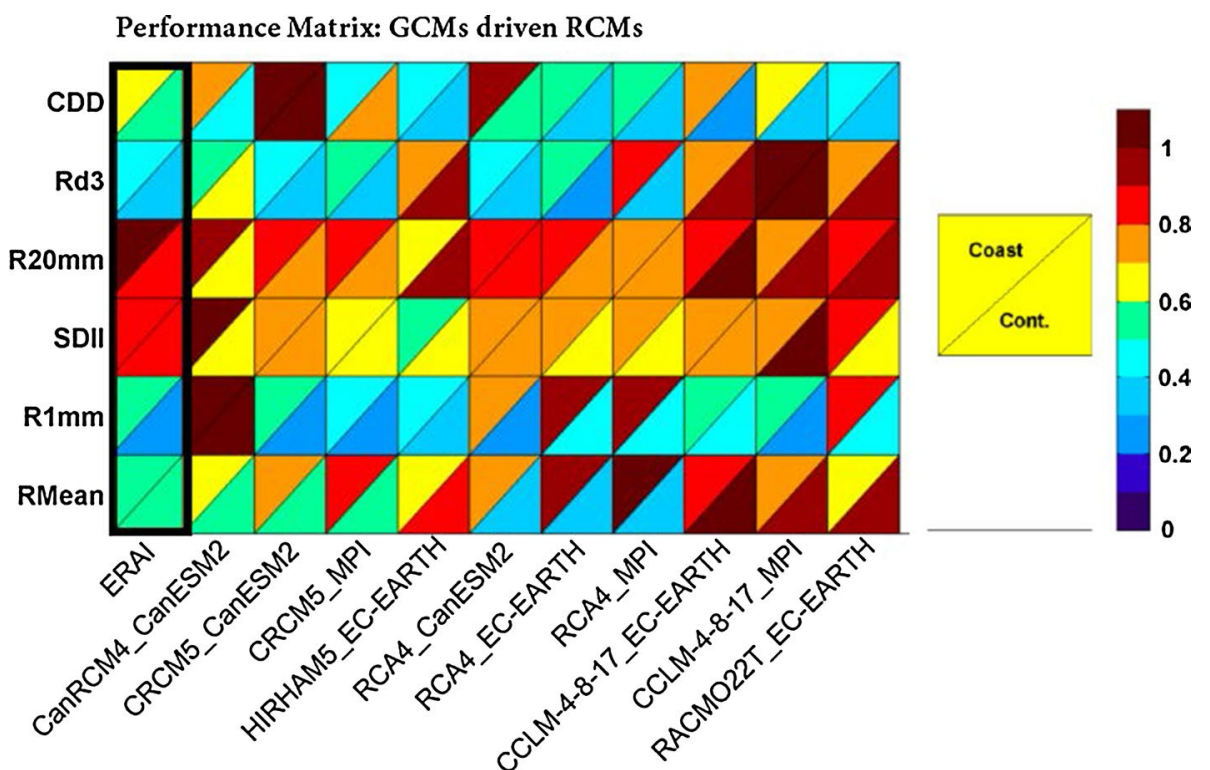

\section{References}

Abdella K, McFarlane N (1997) Parameterization of the surface layer exchange coefficients for atmospheric models. J Atmos Sci 54:1850-1867
Alaka GD, Maloney E (2012) The influence of the MJO on upstream precursors to African easterly waves. J Clim 25:3219-3236

Arora VK, Scinoca JF, Boer GJ, Christian JR, Denman KL, Flato GM, Kharin VV, Lee WG, Merryfield WJ (2011) Carbon emission limits required to satisfy future representative concentration 
pathways of greenhouse gases. Geophys Res Lett 38:L05805. doi:10.1029/2010GL046270

Baldauf M, Schulz JP (2004) Prognostic precipitation in the LokalModell (LM) of DWD. COSMO Newslett 4:177-180

Barker HW, Cole JNS, Morcrette J-J, Pincus R, Raisanen P, von Salzen K, Vaillancourt PA (2008) The Monte Carlo independent column approximation: an assessment using several global atmospheric models. QJR Meteorol Soc 134:1463-1478

BBC News (2009) UN warns on West Africa floods. http://news.bbc. co.uk/2/hi/africa/8239552.stm. Accessed 5 September 2009

Benoit R, Cote J, Mailhot J (1989) Inclusion of a TKE boundary layer parameterization in the Canadian regional finite-element model. Mon Weather Rev 117:1726-1750

Biasutti M, Sobel AH (2009) Delayed Sahel rainfall and global seasonal cycle in a warmer climate. Geophys Res Lett 36:L23707. doi:10.1029/2009GL041303

Bock O, Guichard F, Janicot S, Lafore J-P, Bouin M-N, Sultan B (2007) Multiscale analysis of precipitable water vapor over Africa from GPS data and ECMWF analyses. Geophys Res Lett 34:L09705. doi:10.1029/2006GL028039

Bock O, Bouin MN, Doerflinger E, Collard P, Masson F, Meynadier R, Nahmani S, Koité M, Gaptia K, Balawan L, Didé F, Ouedraogo D, Pokperlaar S, Ngamini J-B, Lafore JP, Janicot S, Guichard F, Nuret M (2008) West African monsoon observed with ground-based GPS receivers during African Monsoon Multidisciplinary Analysis (AMMA). J Geophys Res 113:D21105. doi:10.1029/2008JD010327

Burpee RW (1972) The origin and structure of easterly waves in the lower troposphere of North Africa. J Atmos Sci 29:77-90

Buzzi M, Rotach MW, Raschendorfer M, Holtslag AAM (2011) Evaluation of the COSMO-SC turbulence scheme in a shear-driven stable boundary layer. Meteorol Z 20:335-350

Chauvin F, Roehrig R, Lafore J-P (2010) Intraseasonal variability of the Saharan heat low and its link with mid-latitudes. J Climate 23:2544-2561

Cornforth R, Thorncroft CD, Hoskins BJ (2009) The impact of moist processes on the African easterly jet-African easterly wave system. Q J R Meteorol Soc 135:894-913

Couvreux F, Guichard F, Bock O, Campistron B, Lafore J-P, Redelsperger J-L (2010) Synoptic variability of the monsoon flux over West Africa prior to the onset. Q J R Meteorol Soc 136:159-173. doi:10.1002/qj.473

Crétat J, Vizy EK, Cook KH (2013) How well are daily intense rainfall events captured by current climate models over Africa? Clim Dyn. doi:10.1007/s00382-013-1796-1797

Crétat J, Vizy EK, Cook KH (2015) The relationship between African easterly waves and daily rainfall over West Africa: observations and regional climate simulations. Clim Dyn. doi:10.1007/ s00382-014-2120-x

Cuxart J, Bougeault P, Redelsperger J-L (2000) A turbulence scheme allowing for mesoscale and large-eddy simulations. Q J R Meteorol Soc 126:1-30

Dee DP, Uppala SM, Simmons AJ, Berrisford P, Poli P, Kobayashi S, Andrae U, Balmaseda MA, Balsamo G, Bauer P, Bechtold P, Beljaars ACM, van de Berg L, Bidlot J, Bormann N, Delsol C, Dragani R, Fuentes M, Geer AJ, Haimberger L, Healy SB, Hersbach H, Holm EV, Isaksen L, Kallberg P, Kohler M, Matricardi M, McNally AP, Monge-Sanz BM, Morcrette J-J, Park B-K, Peubey C, de Rosnay P, Tavolato C, Thépaut J-N, Vitart $\mathrm{F}$ (2011) The ERA-interim reanalysis: configuration and performance of the data assimilation system. Q J R Meteorol Soc 137:553-597

Delage Y (1997) Parameterising sub-grid scale vertical transport in atmospheric models under statically stable conditions. Bound Layer Meteorol 82:23-48
Delage Y, Girard C (1992) Stability functions correct at the free convection limit and consistent for both the surface and Ekman layers. Bound Layer Meteorol 58:19-31

Di Luca A, de Elía R, Laprise R (2015) Challenges in the quest for added value of regional climate dynamical downscaling. Curr Clim Change Rep 1:10-21. doi:10.1007/s40641-015-0003-9

Diaconescu EP, Gachon P, Scinocca J, Laprise R (2015) Evaluation of daily precipitation statistics and monsoon onset/retreat over western Sahel in multiple data sets. Clim Dyn 45:1325-1354. doi:10.1007/s00382-014-2383-2

Diallo I, Sylla MB, Giorgi F, Gaye AT, Camara M (2012) Multimodel GCM-RCM ensemble based projections of temperature and precipitation over West Africa for early 21st century. Int J Geophys. doi:10.1155/2012/972896

Diallo I, Bain CL, Gaye AT, Moufouma-Okia W, Niang C, Dieng MDB, Graham R (2014) Simulation of the West African monsoon onset using the HadGEM3-RA regional climate model. Clim Dyn 43(3-4):575

Diedhiou A, Janicot S, Viltard A, de Felice P, Laurent H (1999) Easterly wave regimes and associated convection over West Africa and tropical Atlantic: results from the NCEP/NCAR and ECMWF reanalyses. Clim Dyn 15:795-822

Doms G, Förstner J, Heise E, Herzog H-J, Raschendorfer M, Schrodin R, Reinhardt T,Vogel G (2007) A description of the nonhydrostatic regional model LM (version 3.20). Part II: physical parameterization. http://www.cosmomodel.org/content/model/ documentation/core/cosmoPhysParamtr.pdf

Druyan LM, Feng FJ, Xue Y, Cook KH, Hagos SM, Konaré A, Moufouma-Okia W, Rowell DP, Vizy EK (2010) Ibrah SS (2010) The WAMME regional model intercomparison study. Clim Dyn 35:175-192. doi:10.1007/s00382-009-0676-7

Duchon CE (1979) Lanczos filtering in one and two dimensions. J Appl Meteorol 18:1016-1022

ECMWF, cited 2006: IFS documentation-Cy31r1 operational implementation PART IV: physical processes. http://www.ecmwf.int/ research/ifsdocs/CY31r1/PHYSICS/IFSPart4.pdf

Fink A, Reiner A (2003) Spatio-temporal variability of the relation between African easterly waves and West African squall lines in 1998-1999. J Geophys Res. doi:10.1029/2002JD002816

Fitzpatrick RGJ, Bain C, Knippertz P, Marsham JH, Parker DJ (2015) The West African monsoon onset: a concise comparison of definitions. J Clim. doi:10.1175/JCLI-D-15-0265.1

Flaounas E, Bastin S, Janicot S (2011) Regional climate modelling of the 2006 West African monsoon: sensitivity to convection and planetary boundary layer parameterisation using WRF. Clim Dyn 36:1083-1105. doi:10.1007/s00382-010-0785-3

Flaounas E, Janicot S, Bastin S, Roca R, Mohino E (2012) The role of the Indian monsoon onset in the West African monsoon onset: observations and AGCM nudged simulations. Clim Dyn 38(5-6):965-983

Fouquart Y, Bonnel B (1980) Computations of solar heating of the earth's atmosphere: a new parameterization. Beitr Phys Atmos 53:35-62

Gachon P, Gauthier N, Bokoye AI, Parishkura D, Cotnoir A, Tremblay Y, Vigeant G (2007) Groupe de travail II -Variabilité, extrêmes et changements climatiques au Sahel: de l'observation à la modélisation, 218 p. Dans: Rapport des contributions canadiennes au projet ACDI-CILSS (\#A030978-002); Appui aux capacités d'adaptation aux changements climatiques. Montréal: Environnement Canada, tome II

Gallée H, Moufouma-Okia W, Bechtold P, Brasseur O, Dupays I (2004) A high-resolution simulation of a West African rainy season using a regional climate model. J Geophys Res 109:D05108. doi:10.1029/2003JD004020

Galvin JFP (2010) Two easterly waves in West Africa in summer 2009. Weather 65:219-227. doi:10.1002/wea.605 
Gbobaniyi E, Sarr A, Sylla MB, Diallo I, Lennard C, Dosio A, Dhiédiou A, Kamga A, Klutse NAB, Hewitson B, Nikulin G, Lamptey B (2013) Climatology, annual cycle and interannual variability of precipitation and temperature in CORDEX simulations over West Africa. Int J Climatol 34:2241-2257. doi: $10.1002 /$ joc. 3834

Giorgi F, Jones C, Asrar GR (2009) Addressing climate information needs at the regional level: the CORDEX framework. World Meteorol Org Bull 58:175

Gleckler PJ, Taylor KE, Doutriaux C (2008) Performance metrics for climate models. J Geophys Res 113:1-20. doi:10.1029/200 7JD008972

Guichard F, Kergoat L, Mougin E, Timouk F, Baup F, Hiernaux P, Lavenu F (2009) Surface thermodynamics and radiative budget in the Sahelian Gourma: seasonal and diurnal cycles. J Hydrol 375:161-177. doi:10.1016/j.jhydrol.2008.09.007

Hagemann S (2002) An improved land surface parameter dataset for global and regional climate models. MPI Rep 336:21

Hazeleger W et al (2012) EC-Earth V2.2: description and validation of a new seamless earth system prediction model. Clim Dyn 39(11):2611-2629

Hernández-Díaz L, Laprise R, Sushama L, Martynov A, Winger K, Dugas B (2013) Climate simulation over CORDEX Africa domain using the fifth-generation Canadian Regional Climate Model (CRCM5). Clim Dyn 40(5-6):1415-1433. doi:10.1007/ s00382-012-1387-z

Herzog HJ, Vogel G, Schubert U (2002) LLM-a non hydrostatic model applied to high-resolving simulations of turbulent fluxes over heterogeneous terrain. Theor Appl Climatol 73:67-86

Holloway CE, Neelin JD (2007) The convective cold top and quasi equilibrium. J Atmos Sci 64:1467-1487

Hourdin F, Musat I, Grandpeix J-Y, Polcher J, Guichard F, Favot F, Marquet P, Boone A, Lafore J-P, Redelsperger J-L, Ruti PM, Dell'aquila A, Filiberti M-A, Pham M, Doval TL, Traoré AK, Gallée H (2010) AMMA-model intercomparison project. Bull Am Meteorol Soc 91:95-104. doi:10.1175/2009BAMS2791.1

Hsieh J-S, Cook KH (2007) A study of the energetics of African easterly waves using a regional climate model. J Atmos Sci 64:421-440

Huffman GJ, Adler RF, Morrissey MM, Bolvin DT, Curtis S, Joyce R, McGavock B, Susskind J (2001) Global precipitation at one degree daily resolution from multisatellite observations. $\mathbf{J}$ Hydrometeorol 2:36-50

Huffman GJ, Adler RF, Bolvin DT, Gu G, Nelkin EJ, Bowman KP, Stocker EF, Wolff DB (2007) The TRMM multi-satellite precipitation analysis: quasi-global, multi-year, combined-sensor precipitation estimates at fine scale. J Hydrometeorol 8:33-55

Jakob C, Siebesma AP (2003) A new subcloud model for mass-flux convection schemes: influence on triggering, updraft properties, and model climate. Am Meteorol Soc 131:2765-2778

Janicot S, Mounier F, Hall N, Leroux S, Sultan B, Kiladis G (2009) The West African monsoon dynamics. Part IV: analysis of 25-90-day variability of convection and the role of the Indian monsoon. J Clim 22:1541-1565

Jungclaus JH, Fischer N, Haak H, Lohmann K, Marotzke J, Matei D, Mikolajewicz U, Notz D, von Storch J-S (2013) Characteristics of the ocean simulations in the Max Planck Institute Ocean Model (MPIOM) the ocean component of the MPI-Earth system model. J Adv Model Earth Syst 5(2):422-446

Kain JS, Fritsch JM (1990) A one-dimensional entraining/detraining plume model and its application in convective parameterization. J Atmos Sci 47:2784-2802

Kain JS, Fritsch JM (1993) Convective parameterization for mesoscale models: the Kain-Fritsch scheme. The representation of cumulus convection in numerical models. Meteorological monography, No. 24, American Meteorological Society, pp 165-170
Klutse NB, Sylla MB, Sarr A, Diedhiou A, Kamga A, Abdou A, Lamptey B, Gbobaniyi EO, Owusu K, Lennard Ch, Hewiston B, Dosio A, Nikulin G, Panitz H-J, Buechner M (2015) Daily characteristics of West African monsoon rainfall in CORDEX regional climate models. Theor Appl Climatol. doi:10.1007/ s00704-014-1352-3

Kuo HL (1965) On formation and intensification of tropical cyclones through latent heat release by cumulus convection. J Atmos Sci 22:40-63

Laprise R, Hernández-Díaz L, Tete K, Sushama L, Šeparović L, Martynov A, Winger K, Valin M (2013) Climate projections over CORDEX Africa domain using the fifth-generation Canadian Regional Climate Model (CRCM5). Clim Dyn 41(11):3219 3246. doi:10.1007/s00382-012-16512. http://link.springer.com/ article/10.1007\%2Fs00382-012-1651-2

Leroux S, Hall NMJ (2009) On the relationship between African easterly waves and the African easterly jet. J Atmos Sci 66:2303-2316

Leroux S, Hall NMJ, Kiladis G (2010) A climatological study of transient mean-flow interactions over West Africa. Q J R Meteorol Soc 136(s1):397-410. doi:10.1002/qj.474

Li J, Barker HW (2005) A radiation algorithm with correlated k-distribution. Part I: local thermal equilibrium. J Atmos Sci 62:286-309

Liebmann B, Marengo JA (2001) Interannual variability of the rainy season and rainfall in Brazilian Amazon basin. J Clim 14:4308-4318

Madden RA, Julian PR (1971) Description of a 40-50 day oscillation in the zonal wind in the tropical Pacific. J Atmos Sci 28:702-708

Mariotti L, Diallo I, Coppola E, Giorgi F (2014) Seasonal and intraseasonal changes of African monsoon climates in 21st century CORDEX projections. Clim Change 125(1):53-65

Marteau R, Sultan B, Moron V, Alhassane A, Baron C, Traore SB (2011) The onset of the rainy season and farmers' sowing strategy for pearl millet cultivation in Southwest Niger. Agric For Meteorol 151(10):1356-1369. doi:10.1016/j. agrformet.2011.05.018

Mathon V, Laurent H, Lebel T (2002) Mesoscale convective system rainfall in the Sahel. J Appl Meteorol 41:1081-1092

Matthews AJ (2004) Intraseasonal variability over tropical Africa during northern summer. J Clim 17:2427-2440

McCrary RR, Randall DA, Stan C (2014) Simulations of the West African Monsoon with a superparameterized climate model. Part I: the seasonal cycle. J Clim 27:8303-8322. doi:10.1175/ JCLI-D-13-00676.1

Mekonnen A, Thorncroft CD, Aiyyer AR (2006) Analysis of convection and its association with African easterly waves. J Clim 19:5405-5421

Mlawer EJ, Taubman SJ, Brown PD, Iacono MJ, Clough SA (1997) Radiative transfer for inhomogeneous atmospheres: RRTM, a validated correlated-k model for the longwave. J Geophys Res 102:16663-16682

Moron V, Boyard-Micheau J, Camberlin P, Hernandez V, Leclerc C, Mwongera C, Philippon N, Riglos FF, Sultan B (2015) Ethnographic context and spatial coherence of climate indicators for farming communities-a multi-regional comparative assessment. Clim Risk Manag 8:28-46. doi:10.1016/j.crm.2015.03.001

Mouhamed L, Traore SB, Alhassane A, Sarr B (2013) Evolution of some observed climate extremes in the West African Sahel. Weather Clim Extrem J 1:19-25. doi:10.1016/j. wace.2013.07.005

Mounkaila MS, Abiodun BJ, Omotosho J (2015) Assessing the capability of CORDEX models in simulating onset of rainfall in West Africa. Theoret Appl Climatol 119(1-2):d255

Neelin JD, Peters O, Hales K (2009) The transition to strong convection. J Atmos Sci 66:2367-2384 
Nicholson SE (2013) The West African Sahel: a review of recent studies on the rainfall regime and its interannual variability. ISRN Meteorol. doi:10.1155/2013/453521

Nikulin G, Jones C, Giorgi F, Asrar G, Buchner M, Cerezo-Mota R, Christensen OB, Déqué M, Fernandez J, Hansler A, van Meijgaard E, Samuelsson P, Sylla MB, Sushama L (2012) Precipitation climatology in an ensemble of CORDEX-Africa regional climate simulations. J Clim 25(18):6057-6078

Novella NS, Thiaw W (2012) African rainfall climatology version 2 for famine early warning systems. J Appl Meteorol Climatol 52:588-606

Oettli P, Sultan B, Baron C, Vrac M (2011) Are regional climate models relevant for crop yield prediction in West Africa? Environ Res Lett 6:014008

Paeth H, Born K, Podzun R, Jacob D (2005) Regional dynamical downscaling over West Africa: model evaluation and comparison of wet and dry years. Meteorol Z 14(3):349-367

Paeth H, Hall NMJ, Gaertner MA, Dominguez AM, Moumouni S, Polcher J, Ruti PM, Fink AH, Gosset M, Lebel T, Gaye AT, Rowell DP, Moufouma-Okia W, Jacob D, Rockel B, Giorgi F, Rummukainen M (2011) Progress in regional downscaling of West Africa precipitation. Atmos Sci Lett 12:75-82

Parry ML, Canziani OF, Palutikof JP, van der Linden PJ, Hanson CE (2007) Climate change 2007: impacts, adaptation and vulnerability. Contribution of Working Group II to the fourth assessment report of the Intergovernmental Panel on Climate Change. Cambridge University Press, Cambridge

Pincus R, Barker HW, Morcrette J-J (2003) A fast, flexible, approximate technique for computing radiative transfer in inhomogeneous cloud fields. J Geophys Res. doi:10.1029/2002JD003322

Poan ED, Roehrig R, Couvreux F, Lafore J-P (2013) West African monsoon intraseasonal variability: a precipitable water perspective. J Atmos Sci 70:1035-1052

Poan ED, Lafore J-P, Roehrig R, Couvreux F (2014) Internal processes within the African Easterly Wave system. R Meteorol Soc, Q.J. doi:10.1002/qj.2420

Pohl B, Douville H (2011) Diagnosing GCM errors over West Africa using relaxation experiments. Part II: intraseasonal variability and African easterly waves. Clim Dyn 37:1313-1334. doi:10.1007/s00382-011-1106-1

Rasch PJ, Kristjánsson JE (1998) A comparison of the CCM3 model climate using diagnosed and predicted condensate parameterizations. J Clim 11:1587-1614

Redelsperger J-L, Diongue A, Diedhiou A, Ceron J-P, Diop M, Gueremy J-F, Lafore J-P (2002) Multi-scale description of a Sahelian weather system representative of the West African monsoon. Q J R Meteorol Soc 128:1229-1258

Reed RJ, Norquist DC, Recker EE (1977) The structure and properties of African wavedisturbance as observed during phase III of GATE. Mon Wea Rev 105:317-333

Ritter B, Geleyn J-F (1992) A comprehensive radiation scheme of numerical weather prediction with potential application to climate simulations. Mon Weather Rev 120:303-325

Roehrig R, Bouniol D, Guichard F, Hourdin F, Redelsperger J-L (2013) The present and future of the West African monsoon: a process-oriented assessment of cmip5 simulations along the AMMA transect. J Clim. doi:10.1175/JCLI-D-12-00505.1

Samuelsson P, Gollvik S, Ullerstig A (2006) The land-surface scheme of the Rossby Centre regional atmospheric climate model (RCA3). SMHI Rep. Met. 122. 25 pp

Sarr MA, Gachon P, Seidou O, Bryant CR, Ndione JA, Comby J (2014) Inconsistent linear trends in Senegalese rainfall indices from 1950 to 2007. Hydrol Sci J. doi:10.1080/02626667.2014.926364

Sass BH, Rontu L, Savijärvi H, Räisänen P (1994) HIRLAM-2 radiation scheme: documentation and tests. SMHI HIRLAM technical report 16, $43 \mathrm{pp}$
Savijärvi H (1990) A fast radiation scheme for mesoscale model and short-range forecast models. J Appl Meterol 29:437-447

Scinocca JF, Kharin VV, Jiao Y, Qian MV, Lazare M, Solheim L, Fato GM, Biner S, Desgagne M, Dugas B (2016) Coordinated global and regional climate modeling. J Clim 29:17-35. doi:10.1175/ JCLI-D-15-0161.1

Shapiro MA, Thorpe AJ (2004) THORPEX International Science Plan Version 3. 2 November 2004. WMO/TD-No.1246, WWRP/THORPEX No. 2. World Meteorological Organization, Geneva, p 51

Sultan B, Janicot S, Diedhiou A (2003) The West African monsoon dynamics. Part I: documentation of intraseasonal variability. J Clim 16:3389-3406

Sultan B, Baron C, Dingkuhn M, Sarr B, Janicot S (2005) Agricultural impacts of large-scale variability of the West African monsoon. Agric For Meteorol 128:93-110. doi:10.1016/j. agrformet.2004.08.005

Sundqvist H, Berge E, Kristjansson JE (1989) Condensation and cloud parameterization studies with a mesoscale numerical weather prediction model. Mon Weather Rev 117:1641-1657

Sylla MB, Gaye AT, Pal JS, Jenkins GS, Bi XQ (2009) High-resolution simulations of west African climate using regional climate model (RegCM3) with different lateral boundary conditions

Sylla MB, Dell'Aquila A, Ruti PM, Giorgi F (2010) Simulation of the intraseasonal and the interannual variability of rainfall over West Africa with a Regional Climate Model (RegCM3) during the monsoon period. Int J Climatol 30:1865-1883

Sylla MB, Giorgi F, Coppola E, Mariotti L (2012) Uncertainties in daily rainfall over Africa: assessment of gridded observation products and evaluation of a regional climate model simulation. Int J Climatol. doi:10.1002/joc.3551

Taylor CM, Gounou A, Guichard F, Harris PP, Ellis RJ, Couvreux F, De Kauwe M (2011) Frequency of Sahelian storm initiation enhanced over mesoscale soil-moisture patterns. Nat Geosci 4:430-433. doi:10.1038/ngeo1173

Thorncroft CD, Blackburn M (1999) Maintenance of the African easterly jet. Q J R Meteorol Soc 125:763-786

Tiedtke M (1989) A comprehensive mass flux scheme for cumulus parameterization in large-scale models. Mon Weather Rev 117:1779-1800

Tiedtke M (1993) Representation of clouds in large-scale models. Mon Weather Rev 121:3040-3061

Tompkins AM (2002) A prognostic parameterization for the subgridscale variability of water vapor and clouds in large-scale models and its use to diagnose cloud cover. J Atmos Sci 59:1917-1942

Torrence C, Compo GP (1998) A practical guide to wavelet analysis. Bull Am Meterol Soc 79:61-78

Vellinga M, Arribas A, Graham R (2013) Seasonal forecasts for regional onset of the West African monsoon. Clim Dyn 40:3047-3070. doi:10.1007/s00382-012-1520z

Verseghy DL (2000) The Canadian Land Surface Scheme (CLASS): its history and future. Atmos Ocean 38:1-13

Vizy EK, Cook KH, Crétat J, Neupane N (2013) Projections of a wetter Sahel in the 21st century from global and regional models. J Clim. doi:10.1175/JCLI-D-12-00533.1

von Salzen K, McFarlane NA (2002) Parameterization of the bulk effects of lateral and cloud-top entrainment in transient shallow cumulus clouds. J Atmos Sci 59:1405-1429

von Salzen K, Scinocca JF, McFarlane NA, Li J, Cole JNS, Plummer D, Reader MC, Ma X, Lazare M, Solheim L (2013) The Canadian fourth generation atmospheric global climate model (CanAM4). Part I: representation of physical processes. Atmos Ocean 51(1):104-125. doi:10.1080/07055900.2012.755610

Zhang GJ, McFarlane NA (1995) Sensitivity of climate simulations to the parametrization of cumulus convection in the CCC-GCM. Atmos Ocean 3:407-446 